\title{
Plastic contamination of the Galapagos marine food web and the relative risks to native species
}

\section{Jen Jones}

University of Exeter

\section{Adam Porter}

University of Exeter https://orcid.org/0000-0002-8493-3216

\section{Juan Muñoz-Pérez}

Universidad San Francisco de Quito (USFQ) \& UNC-Chapel Hill Galápagos Science Center (GSC); Faculty of Science and Engineering, University of the Sunshine Coast https://orcid.org/0000-0002-9792-5653

\section{Daniela Alarcón-Ruales}

Galapagos Science Center GSC

\section{Tamara Galloway}

University of Exeter

\section{Brendan Godley}

University of Exeter

\section{David Santillo}

Greenpeace Research Laboratories

\section{Jessica Vagg}

University of Exeter

Ceri Lewis ( $\square$ c.n.lewis@exeter.ac.uk)

University of Exeter https://orcid.org/0000-0002-3564-2906

\section{Article}

Keywords: Galapagos Islands, plastic contamination, marine ecosystem

Posted Date: December 2nd, 2020

DOl: https://doi.org/10.21203/rs.3.rs-111140/v1

License: (1) (i) This work is licensed under a Creative Commons Attribution 4.0 International License. Read Full License 


\section{Abstract}

Ecuador's Galapagos Islands and their unique biodiversity are a global conservation priority. We investigated the presence, partitioning and environmental drivers of plastic contamination across the marine ecosystem, designing a systematic risk scoring analysis to identify the most vulnerable species. Beach contamination varied by site (macroplastic 0 - 0.66 items.m-2, large microplastics 0 - 448.8 particles.m-2, small microplastics $0-74.6$ particles.kg-1), with high plastic accumulation on east-facing beaches indicating input from the Humboldt Current. Local littering and waste management leakages accounted for $2 \%$ of macroplastic. Microplastics (including synthetic cellulosics) were prevalent in sediments (6.7 - 86.7 particles.kg-1) and surface seawater (0.04 - 0.89 particles.m-3), with elevated concentrations in the harbour suggesting local input. Microplastics were present in all seven marine invertebrate species examined, found in $52 \%$ of individuals $(n=123)$. Risk scoring identified 32 species in need of urgent, targeted monitoring and mitigation including pinnipeds, seabirds, turtles, sharks and corals.

\section{Introduction}

With the input of plastic pollution to aquatic systems predicted to triple in the next twenty years in a 'business as usual' scenario ${ }^{1}$, negative impacts on marine food webs, ecosystem services, and coastal economies are of increasing global concern ${ }^{2}$. Islands are host to $37 \%$ of all critically endangered species and have seen over half of recent extinctions due to the increased sensitivity of endemic species to anthropogenic stressors ${ }^{3}$. Although far from major population centres, some of the highest levels of plastic pollution have been reported on remote oceanic islands e.g. Henderson Island, where ca. 4,500 plastic pieces. $\mathrm{m}^{-2}$ were reported buried in surface beach sediment ${ }^{4}$. Plastics pose a synergistic threat to fragile systems via physical habitat contamination, injury risk and as a potential vector for sorbed chemicals, pathogens and invasive species ${ }^{5,6}$.

The Galapagos Islands, situated $930 \mathrm{~km}$ off the coast of Ecuador in the Pacific Ocean, are a UNESCO World Heritage Site famous for their endemic biodiversity. The interaction of several currents and strong upwelling systems drives the high productivity of the Galapagos Marine Reserve ${ }^{7}$, home to 22 marine species listed as endangered on the IUCN Red List. Anthropogenic pressures are mounting, with rising visitor numbers increasing the risk of invasive species introductions ${ }^{8}$, escalating demand on resources including sanitation systems ${ }^{9}$ and also, the occurrence of illegal fishing despite legislative protection ${ }^{10}$. Native fauna are particularly vulnerable to marine pollution, for example, biomonitoring revealed elevated concentrations of persistent organic pollutants including PCBs in the blubber of Galapagos sea lions (Zalophus wollebaeki) ${ }^{11}$ and mass marine iguana (Amblyrhynchus cristatus) mortality was reported following a major oil spill in 2001 despite exposure to only trace concentrations ${ }^{12}$. Impacts from plastic contamination could have major ecological and socioeconomic consequences, particularly for the tourism industry that comprises $80 \%$ of the local economy ${ }^{13}$. 
Modelling approaches using virtual floating plastics transported on ocean surface currents have identified continental inputs as a major source of incoming plastic pollution to Galapagos, mostly from southern Ecuador and northern Peru where plastic leaked into the marine environment could arrive within a few months ${ }^{14}$. Together, Ecuador and Peru generated an estimated 304,000 tonnes of mismanaged coastal plastic waste in 2010 , projected to increase to 558,000 tonnes by $2025^{15}$. Models suggest that only a small amount of plastic is entering Galapagos from known industrial fishing grounds but this does not reconcile with unpublished coastal clean-up data or archaeological analysis of macroplastic items that suggest maritime sources are likely a significant contributor ${ }^{14,16}$.

Plastic pollution is a complex mixture of heterogenous materials with a range of physical and chemical properties that can affect movement and accumulation in the environment and thus, potential impacts to ecosystems ${ }^{17}$. Microplastics enter the marine environment from many sources such as river systems, agricultural run-off, wastewater or even atmospheric deposition ${ }^{18}$. They may also be generated in the environment i.e. from fragmentation of larger plastic items, processes that are likely to be accelerated on Galapagos' beaches due to high equatorial solar irradiation levels, high oxygen availability and mechanical stress from wave action in the surf zone ${ }^{19,20}$. Here, our aim was to investigate the habitat partitioning, distribution and environmental drivers of plastic contamination in the Galapagos marine ecosystem at an island scale, focusing on San Cristobal in the east of the Archipelago, situated in the pathway of the Humboldt Current (Fig. 1A). San Cristobal has areas of high conservation importance for endangered species, hosting nurseries for scalloped hammerhead sharks (Sphyrna lewini), foraging grounds for green turtles (Chelonia mydas), the largest Galapagos sea lion (Z. wollebaeki) colony residing in the harbour and hosts two unique marine iguana ( $A$. cristatus) subspecies. Field sampling was conducted between May 2018 and April 2019 across both tourist and remote (unvisited) sites (Fig. 1B) to investigate partitioning of plastic pollution across beaches, surface seawater, sediments and bioaccumulation in marine invertebrates. We tested the hypotheses that the Humboldt Current is a major driver for the spatial distribution of plastic in this part of the Galapagos Marine Reserve and that local inputs are currently low.

Linking plastic contamination data to health impacts for individual organisms remains a challenge in the field, given multiple environmental stressors and analytical challenges of confirming microplastic ingestion and measuring associated harm. To address this issue, and to allow targeting of research, monitoring and mitigation efforts, a systematic risk scoring analysis was developed based on species distribution information, IUCN Red list species vulnerability and harm data to rank 3,184 Galapagos marine species (337 endemic) threatened by exposure to plastic pollution to identify species at high risk.

\section{Results And Discussion}

\section{Macroplastic on the Beach: Distribution, Composition \& Sources}


Macroplastic contamination (items and fragments $>5 \mathrm{~mm}$ ) was recorded on 13 out of 14 sandy beaches sampled, with a total of 4,610 items collected from the back-beach vegetation to the water line along $100 \mathrm{~m}$ transects. Abundance was more than five-fold higher on east-facing beaches exposed to the Humboldt Current (mean 0.27 items. $\left.\mathrm{m}^{-2}\right)$ than on southern $(0.05$ items. $\left.\mathrm{m}^{-2}\right)$ or northern/ western-facing beaches (0.02 items.m-2, Fig. 2). A generalised linear model (GLM) examining possible environmental drivers of plastic abundance by site using explanatory variables such as beach aspect, grain size and distance from harbour, revealed that none of the measured parameters were statistically significant drivers of macroplastic distribution (see methods and Supplementary Table 1). Items and fragments were categorised by type and possible source using a modified OSPAR methodology as per Watts et al. ${ }^{21}$ (Fig. 2 , Supplementary Table 2). Assigning source (i.e. usage and responsible industry) and the mechanisms of release and pathways within the environment are difficult for plastics, for example, a bottle could be littered on the beach, thrown overboard or carried on currents from riverine inputs. Only items that did not show evidence of prolonged marine exposure e.g. no epibionts, no yellowing, no degradation of labels etc. were assigned to 'local' littering and waste management leakages, which represented just $2 \%$ of the items recorded. Tourist beaches were generally clean, as described by Mestanza et al. ${ }^{22}$, a likely result of small population size, elevated environmental expectations of visitors and good provision of bins and awareness messaging although due to accessibility, tourist beaches also tend to be on sheltered coasts that are less likely to receive incoming water-borne pollution. Galapagos National Park Guides and community groups do regular beach-cleans, but accessible sites do not generally include remote, east-facing beaches.

The majority of beach macroplastic was classified as 'unsourced' (88\%) i.e. from external sources to the Galapagos Marine Reserve; comprising mostly weathered hard plastic fragments ( $49 \%$ of total, $n=2,240$ ) or items without an obvious original source (Fig. 2). Drinks bottles, caps and sealing rings were common (53\% of unsourced items, $n=1,248)$. Discarded fishing gear was found in lower quantities than reported for other oceanic islands 23,24 ; accounting for $10 \%$ of macroplastic by frequency ( $\mathrm{n}=457$, mostly ropes), found along all coastlines. Given the protection within the marine reserve from industrial fishing and the small size of the 
artisanal fleet, gear loss and irresponsible disposal appears to be low locally. There is evidence of some connectivity with continental fisheries, as floating polypropylene eel traps, a gear not used in Galapagos, were recovered from one east-facing beach $(n=20$; Site 16, Fig. 1B). A beached Fish Aggregating Device (FAD) was also observed; although illegal in Galapagos, FADs have been increasingly reported in recent decades ${ }^{25}$ and represent a major ghost-fishing risk whilst in the water, an entanglement risk on the beach and a major future source of microplastics.

\section{Microplastic on the Beach: Distribution, Composition \& Sources}

Large microplastics (1 - $5 \mathrm{~mm}$ ) sieved from the surface $5 \mathrm{~cm}$ of beach sediment were found at 11 out of 15 sites and $>95 \%$ were from secondary sources i.e. a result of fragmentation $(\mathrm{n}=$ 1,$694 ; 78 \%$ fragments, $13 \%$ fibres, $4 \%$ films and $2 \%$ pellets). The mean concentration was 53 particles. $\mathrm{m}^{-2}$, but distribution was patchy (Fig. 3Aii). A GLM identified beach aspect as a significant driver of accumulation of large microplastics $(p<0.001$, Supplementary Table 1$)$ with abundance significantly higher on east-facing beaches. More than $92 \%$ of macroplastic ( $5 \%$ sub-sample analysed by Fourier Transform Infra-red spectroscopy; $\mathrm{n}=137$ ) and $80 \%$ of large microplastic ( $n=1,694$ ) was made up of floating petrochemical-based polymers polyethylene and polypropylene (Fig. 3Bi-ii) and were generally white/ black/ blue fragments or blue / green fibres (see Supplementary Fig. 1). This similarity in composition and correlation in abundance of macroplastic and large microplastic (Spearman's rank correlation coefficient; $\mathrm{R}_{\mathrm{s}}=0.794, \mathrm{p}<0.001, \mathrm{df}=14$ ) suggests that macroplastic is fragmenting in situ as has been described in other island systems ${ }^{26}$.

The north-eastern coastline had the highest accumulation of large microplastics; with 808 particles. $\mathrm{m}^{-2}$ collected from one part of Punta Pitt (Site 17). This high concentration is similar to those recorded in Easter Island situated in the plastic accumulation zone of the South Pacific Gyre $\left(805 \text { particles. } \mathrm{m}^{-2} \text { in the top } 2 \mathrm{~cm}\right)^{27}$. This contrasts with sites a few kilometres away where four west-facing beaches had no large microplastic recorded at all (Fig. 3Aii). A 
similar situation has been reported on Henderson Island where the now infamous highly polluted East Beach has accumulated plastic in volumes much higher than the rest of the island $^{26}$, highlighting the importance of location in defining risk.

Smaller microplastic fractions $(<1 \mathrm{~mm})$ in surface beach sediment were present at 14 out of 15 sites with an average island abundance of 74.6 particles. $\mathrm{kg}^{-1}$ (dry weight). Unlike larger particles, this size fraction did not have significantly higher abundance at any site(s), (Fig. 3Aiii). Of the particles extracted $(n=173), 53 \%$ were fragments that were a similar composition to larger beach plastic i.e. mostly polyethylene and polypropylene (Fig. 3Biii). Fibres were mostly anthropogenically modified cellulosics $(60 \%)$, generally associated with textiles $^{28}$.

\section{Seawater Surface \& Seabed Microplastic: Distribution, Composition \& Sources}

Plastic contamination of the seawater surface was measurable at low concentrations at all 17 sites sampled with an island average of 0.16 particles.m ${ }^{-3}$ (Fig. 3Aiv-v). No significant explanatory variables were identified by GLM when models included beach aspect, windward vs leeward orientation, site usage (tourism, remote) or distance from harbour. The harbour (Site 7) had significantly higher seawater surface pollution with a mean concentration of 0.89 particles. $\mathrm{m}^{-3}$ (Kruskall-Wallis test; $\mathrm{H}=33.59, \mathrm{df}=16, \mathrm{p}=0.006$ ) (Fig. 3Aiv) suggesting local inputs such as wastewater outfalls. Seawater surface particles $(n=373)$ included polypropylene and polyethylene fragments (32\%), synthetic cellulosic fibres (24\%), polyester fibres (11\%), polypropylene fibres (11\%) and nylon fibres (7\%) suggesting a mixture of sources (Fig. 2Biv).

Seabed (benthic sediment) pollution was not significantly higher around the populated harbour. The island mean was 35.8 particles. $\mathrm{kg}^{-1}$, (range 6.7 - 86.7 particles. $\mathrm{kg}^{-1}$, Fig. 3Av), 
less than half the concentration recovered from beach sediment. As regularly reported in other studies $^{29}$, over $90 \%$ of benthic microplastic pollution was fibres. The closest spectrum match for $58 \%$ of fibres was polyacrylamide although these are suspected to be more likely cellulosics as polyacrylamide is generally a gel and not commonly found in the environment. Cellulosics (14\%) and polyester fibres (14\%) were confirmed, both high density polymers that are more likely to sink versus the lower density polymers that accumulate at the sea surface and are washed up onto beaches (see Fig. 3Bv). Although floating plastics of all sizes might enter the marine reserve, denser polymers may be more likely to sink out of the water column in coastal sediments, being incorporated in sediment transport processes closer to continental sources $^{30}$. If this is true, benthic pollution in Galapagos is more likely to be locally generated and warrants further investigation of wastewater, agricultural run-off and contamination of terrestrial systems.

Our data suggest that larger plastic distribution agrees closely with modelled predictions of Humboldt Current input to the Galapagos Marine Reserve and confirms that local inputs are measurable but currently low. Distribution of smaller particles across different habitats cannot be solely explained by incoming transport on currents, likely subjected to different fragmentation and transport processes.

\section{Contamination of Galapagos marine invertebrates}

We examined seven representative invertebrate species for microplastic contamination comprising suspension and filter feeders (barnacles and oysters, $n=25$ ), grazers (urchins, chitons and gastropod snails, $\mathrm{n}=49$ ) and a surface deposit feeder (sea cucumber, $\mathrm{n}=49$ ) from six sites around San Cristobal. All species contained synthetic particles and all but the chiton (Chiton sulcatus) contained petrochemical-based microplastics. Overall, mean incidence of ingestion was $52 \%$ across all individuals. Giant barnacles (Megabalanus peninsularis) had the highest proportion of individuals containing microplastics (83\%) followed by pencil urchins 
(Eucidaris galapagensi) (60\%) (Fig. 4A). There were no significant drivers influencing particle uptake in marine invertebrates when tested by GLM and no correlation was found between number of particles and invertebrate dry weight (g) (Supplementary Fig. 3, Supplementary Table 4) acknowledging that our data is limited to small sample sizes for some species.

Suspension and filter feeders are exposed to particles in suspension, sinking through the water column or those resuspended from the seabed. Goose barnacles (Lepas anatifera), giant barnacles (M. peninsularis) and palmate oysters (Saccostrea palmula) contained only fibres (19 particles extracted) with mean abundance per individual of $0.72,1.17$ and 0.67 respectively (Fig. 5A), a low rate of contamination compared to other studies, particularly oysters where up to 35 particles per individual have been recorded ${ }^{31}$. Extracted fibres were mostly higher density polymers such as modified cellulosics (70\%) and nylon (11\%) (Fig. 5B), similar to the polymer composition of particles from benthic sediment, echoing the relationship observed in a UK study of mussels (Mytilus edulis) ${ }^{29}$. Fibres have a larger surface area than fragments and a greater propensity to become bio-fouled and sink which may increase bioavailability to filter feeders that also play a role in modulating microplastic pathways by drawing down particles to the benthos ${ }^{32}$. Fibres may also be more likely to be retained in organisms or entangled in morphological structures ${ }^{33}$. This was observed in three goose barnacles in our study, where > $1.5 \mathrm{~mm}$ clumps of green polypropylene fibres were extracted (see Fig. 4B) suggesting potential physiological impacts from either gut or gill obstruction, due to the amount accumulated relative to the size of the animal (mean carapace length $12 \mathrm{~mm}$ ).

Particles within grazers (34 extracted) were more diverse in terms of shape (53\% fragments, $44 \%$ fibres), colour and polymer (Supplementary Fig. 3, Fig. 5Bii) than those found within filter feeders. Modified cellulosics were again the most common polymer (26\%), but polyester (13\%), polypropylene (13\%), polyethylene (10\%) and adhesives (19\%) were also found, suggesting grazers are exposed to beach plastics as well as microplastics in the seawater or sediment. The gastropod snails (Nerita scabricosta), chitons and pencil urchins all had an average number of particles per individual less than one (0.64, 0.5, and 0.68 respectively). 
These data are in a similar range to those measured in benthic invertebrates including gastropods and asteroids in the Arctic where species means varied from $0.04-1.67$ particles.ind ${ }^{-1} 34$. No published studies for chitons were found and literature is scarce for urchins however Bour et al. 35 found 0.45 microplastic particles.ind ${ }^{-1}$ in spiny mudlark urchins (Brissopsis lyrifera) in a Norwegian fjord. Grazers might indirectly consume particles associated with dietary items such as algae ${ }^{36}$ or directly from grazing on biofilms formed on macroplastic. Three gastropod snails collected from beach macroplastic contained polypropylene fragments with scouring marks possibly caused by radula. Suspected bite marks were also observed on polypropylene fragments recovered from urchins ( $\mathrm{n}=4$, see Fig. 4B). This represents an ingestion pathway and also a process of mechanical fragmentation, as demonstrated in laboratory studies where a single urchin grazing on macroplastic produced > 90 fragments in 10 days $^{37}$.

A mean of 0.99 particles.ind ${ }^{-1}$ was measured in the sea cucumber (Holothuria kefersteini) with higher contamination in specimens from the polluted, east-facing beach of Rosa Blanca (2.54 particles.ind $\left.{ }^{-1}\right)$ with particles recovered from $100 \%$ of individuals $(n=11)$. These findings are similar to holothurians elsewhere although by no means the highest; Renzi et al. ${ }^{38}$ report particle concentrations of 3.8 - 6.0 particles per individual in the Aeolian Archipelago in the Mediterranean. Extracted particles were a mix of fibres (69\%) and fragments (31\%) that were mostly modified cellulosics (64\%). Sea cucumbers were the only invertebrate to have ingested polystyrene $(11 \%)$, a rare polymer in our study. This differs from the composition of the sediments they inhabit, perhaps suggesting selectivity in their uptake of microplastics, as shown in laboratory studies of deposit feeding species (Holothuria spp.) ${ }^{39}$. The feeding mode of sea cucumbers makes them potentially good indicators for benthic microplastic contamination due to their high throughput of ingested sand. 
Our results illustrate that uptake in marine invertebrates with different feeding modes and habitats is widespread in the Galapagos Marine Reserve although major drivers were not identified. The encounter rate for marine invertebrates are likely to be differently impacted among locations due to different exposure, transport pathways, feeding modes and surrounding environmental factors ${ }^{40}$.

\section{Risk scoring for Galapagos marine fauna}

Due to the ethical and logistical constraints around sampling vulnerable species across the entire marine food web, we devised and undertook a risk scoring analysis for predicting the risk of harm from entanglement (E) and ingestion (I) upon encounter with plastics for marine vertebrates (710 species) and invertebrates (2,474 species). We combined species distribution information (considering endemism as a priority factor) and IUCN Red List status (i.e. vulnerability to anthropogenic stressors) to consider potential population level impacts and combined this with evidence in the literature of documented harm attributed to plastics (i.e. injury or mortality) to species sharing a taxonomic family with Galapagos marine species (see

Methods and Supplementary Table 5 for scoring criteria). Low scores do not necessarily equate to low risk in this analysis, rather that potential negative impacts are unknown due to a lack of evidence. Thirty-two species had a score of greater than 10 (maximum score 27) indicating likelihood of severe injury or death from plastic ingestion or entanglement upon encounter. These included five stony coral species, 15 fish species (13 shark spp.), five reptiles (marine iguana and four sea turtle spp.), five seabirds and two mammals (both pinnipeds) (Fig. 6, listed in Supplementary Table 6).

\section{Marine Invertebrates}

Laboratory micro- and nanoplastics exposure studies demonstrate dose-dependent, chronic sub-lethal health effects such as reduced digestion and disruption of embryonic development for a range of invertebrates including molluscs, crustaceans and annelids at environmentally relevant concentrations 17,41 . Our data demonstrate microplastic uptake across a suite of 
marine invertebrates but linking contamination data to health impacts for individual organisms in the field remains difficult.

Marine invertebrates scored low within our risk scoring analysis with $>95 \%$ species scoring $<$ 4 indicating that the current evidence-base for harm is low for most invertebrates and that research attention has been historically lacking in Galapagos. Additionally, only five Galapagos marine invertebrates are included on the IUCN Red List: the over-exploited brown sea cucumber (Isostichopus fuscus) and four endemic stony coral species including the critically endangered Wellington's solitary coral (Rhizopsammia wellingtoni) and the sun cup coral (Tubastraea floreana); the latter two, being the highest scoring invertebrates in our analysis (both $E=27, I=18$ ). Coral reefs are sparse in Galapagos following population crashes after the 1982 - 1983 El Niño event and have still not recovered in upwelling zones ${ }^{42}$. Ingestion of microplastics in corals has been linked with disturbance of the anthozoan-algae symbiotic relationship 43 , bleaching and tissue necrosis ${ }^{44}$ although encounter rate is likely to be low at the contamination levels we have reported here. Incidences of invertebrate entanglement in plastic are rarely reported with the exception of reef-building corals, where smothering by

plastic debris has been shown to increase disease risk and reef die offs ${ }^{45}$. We observed a Galapagos green sea urchin (Lytechinus semituberculatus) covered in yellow plastic tape (Fig. 7B), emulating typical behaviour of constructing macroalgae 'cloaks' for camouflage in the environment, in this case having presumably the opposite effect. Further research into the harm of plastics for invertebrates is essential to understand population level effects and biological mechanisms behind uptake and egestion that have implications for trophic transfer in the marine food web.

\section{Fish}

Within Galapagos fish, sharks are identified as a priority group for further investigation, representing 12 out of 14 fish species at high risk (scoring $>10$ ) of harm from entanglement and all six of the fish species that scored at high risk of harm from plastic ingestion. Although 
differentiating between entanglement in debris and active fishing gear can be difficult, globally there are increasing reports of shark and ray deaths attributed to ghost-fishing and entanglement ${ }^{46}$. The iconic scalloped hammerhead (Sphyrna lewini) and whale shark (Rhincodon typus) scored highest (both $\mathrm{E}=18, \mathrm{I}=18$ ) due to their conservation status (critically endangered and endangered respectively). In addition to entanglement risk, increased plastic concentrations associated with ocean frontal systems suggest that filterfeeders in those regions such as whale sharks and manta rays may be at increased risk of ingestion ${ }^{47}$. Entanglement has been reported in bream and parrotfish ${ }^{48}$ thus two endemic salemas (Xenichthys agassizi, Xenocys jessiae) are the only non-elasmobranchs to score highly $(\mathrm{E}=12, \mathrm{I}=6)$. We recommend further investigation on the impacts to sharks, commercially exploited fish and important dietary species for endangered megafauna.

\section{Reptiles}

Reptiles are the group considered highest priority for investigation of the impacts of plastic pollution in Galapagos (5 out of 7 spp. scored $>10$; Fig. 6 ), particularly green turtles $(C$. mydas) and hawksbill turtles (Eretmochelys imbricata) (both $\mathrm{E}=18, \mathrm{I}=18$ ). Sea turtles are highly vulnerable to interactions with plastic debris and entanglement in derelict fishing gear (Fig. 7C) although data are scarce for the Eastern Pacific region ${ }^{49}$. Models predict that $52 \%$ of the global sea turtle population have ingested plastics ${ }^{50}$ with consumption of films, fragments, fibres, Styrofoam, sheet-like plastics and bags linked to injury and mortality 51 , with the latter often compared with visual similarities of jellyfish prey. Bags comprised $4 \%$ of the total litter items in our study but density varied highly, probably due to in situ fragmentation. At Puerto Tablas, a known turtle foraging area, we collected 107 bags and bag fragments from just 100 $\mathrm{m}$ of beach, posing a considerable risk if washed back out to sea. Duncan et al. ${ }^{52}$, report microplastic $(<1 \mathrm{~mm}$ ) ingestion in $100 \%$ of sea turtles analysed, comprising seven species and three ocean basins, suggesting that ingestion of smaller particles could be occurring from the environment, associated with algal food for rom trophic transfer from invertebrate prey. 
Due to the lack of familial counterparts, the marine iguana (A. cristatus) $(\mathrm{E}=12, \mathrm{I}=12$ ) is considered to have a comparable risk to green turtles as both are primarily algae eaters, spend time at the sea surface increasing potential encounter rate with floating plastics and nest in similar beach habitats. On San Cristobal, a new marine iguana subspecies has been recently described at one of our most polluted sites, Punta Pitt (A. cristatus godzilla). This subspecies is a major conservation priority due to the very small population size of $<500$ individuals and high predation pressure from feral cats 53 . The additional potential stress from plastic pollution is therefore of high concern particularly when considering the sensitivity of this species to other pollutants ${ }^{12}$.

\section{Birds}

Feeding on floating plastics has been well documented in seabirds, particularly in procellariiformes and models predict that by 2050 , $99 \%$ of seabird species and $90 \%$ of individual birds will be ingesting plastics ${ }^{54}$. Galapagos hosts the world's largest breeding colony of the critically endangered waved albatross (Phoebastria irrorata) $(E=18, I=27$ ) and Galapagos petrel (Pterodroma phaeopygia) ( $\mathrm{E}=18$, I = 18), both species known to forage in the Humboldt Current System at increased risk of encounter with floating plastics and at risk of bycatch in fishing grounds outside of the protection of the marine reserve. In addition to the risk of injury for the ingesting adult, there are intergenerational risks from passing plastics to offspring $^{55}$. The Galapagos penguin (Spheniscus mendiculus) scored highly ( $\mathrm{E}=18, \mathrm{I}=18$ ), with evidence from the closely related Magellanic penguin (S. magellanicus) where $15 \%$ of stranded birds $(\mathrm{n}=175)$ had ingested plastic with demonstrated pathology ${ }^{56}$. Threat of entanglement is high for penguins and the flightless cormorant (Phalacrocorax harrisi) $(\mathrm{E}=18$, I = 12), with most interactions of similar species with fishing lines ${ }^{57}$. Integration of plastic debris into nests (Fig. 6D) could introduce entanglement and chemical threats, although direct harm has not been quantified. Observed at several of our most contaminated sampling sites, 
the world's rarest seagull, the lava gull (Leucophaeus fuliginosus) $(\mathrm{E}=18, \mathrm{I}=18$ ) is at risk from ingestion and entanglement as reported in Patagonia with discarded fishery gear causing mortality in closely related kelp gulls (Larus dominicanus) ${ }^{58}$.

\section{Mammals}

The high risk to the Galapagos sea lion $(E=27, I=18)$ from plastic pollution is evidenced by 251 harmful entanglement interactions recorded between 1995 and 2003, 54\% linked to fishery litter and $46 \%$ to other litter such as packaging (see Fig. 6A) ${ }^{59}$. This species is often found close to population centres, particularly the harbour in San Cristobal that hosts one of the largest colonies. Anecdotal observations of entanglement are frequent and other studies suggest that encounters are likely to be higher in juveniles ${ }^{60}$. Although no published accounts of harmful interactions for the Galapagos fur seal (Arctocephalus galapagoensis) $(\mathrm{E}=27, \mathrm{I}=$ 18) were found, there are numerous examples from other Arctocephalus spp. for both entanglement (mostly in fishing gear) and ingestion evidenced by small plastics $<5 \mathrm{~mm}$ recorded in scats in Macquarie Island in the southwest Pacific ${ }^{61}$ suggesting trophic transfer.

This work demonstrates that our novel rapid assessment tool provides a qualitative way of scoring species risk from plastics according to the global evidence base. This could support plastic pollution risk mitigation for species and presents a method that could be applied to other vulnerable systems. Although biased by the most studied taxa i.e. coastal species or those that are likely to beach following injury or mortality, this method highlights rangerestricted species that are vulnerable to a suite of known conservation threats via the proxy of IUCN Red List data. In addition to highlighting species in Galapagos that are of highest concern, it also highlights the dearth of data for many species groups, particularly for invertebrates and fish.

\section{Conclusions And Recommendations}


Our findings support the modelled predictions that the Humboldt Current is a major driver for the rate and spatial distribution of plastic accumulation in this part of the Galapagos Marine Reserve and highlights the need for a regional approach in the Eastern Pacific to: (i) assess the sources and pathways of pollution; (ii) evaluate ecological and socioeconomic impacts and (iii) work towards mitigation initiatives at an effective scale. Our data suggest that fragmentation of plastic items takes place in situ on beaches in Galapagos underlining the need for continued clean-up to reduce risks for wildlife and reduce future generation of microplastics. However, this is expensive financially, in terms of carbon footprint and by way of waste management infrastructure requirements that are already over-burdened.

Levels of plastic contamination reported here are likely an under-estimate due to methodological limitations and the difficulty of accurate polymer identification, particularly for smaller particles and those extracted from organisms. We observed significant accumulations of plastics on rocky lava shores, in mangroves and associated with back-beach vegetation highlighting the need to quantify these temporary sinks that represent key habitats for marine species. We acknowledge that there is a wider suite of risks from plastic contamination than solely ingestion and entanglement that were considered in the risk scoring analysis. Plastic debris acts as a new substrate for rafting organisms ${ }^{62}$, of particular concern in Galapagos with marine ecosystems highly vulnerable to non-native species invasions ${ }^{8}$. Galapagos ecosystems are highly impacted by the El Niño Southern Oscillation causing past ecological cascades and regime shifts ${ }^{63}$. The multi-stressor effect of warming, food limitation and heightened disease risk could be further exacerbated by plastics and other pollutants in the environment. Several high-risk marine species in our assessment including marine iguanas and Galapagos penguins are already heavily compromised during these climatic fluctuations ${ }^{64}$.

To improve the outlook for the marine wildlife of Galapagos, we recommend: (i) the extension of plastic and ecological surveys around the Archipelago to incorporate further important habitats for priority species and investigate seasonal and inter-annual variation; (ii) the refinement of oceanographic modelling to establish more detailed plastic pathways particularly from industrial fishery sources; (iii) focused investigation on key species to define risks and design interventions; (iv) the development of tools such as predictive models or databases e.g. for strandings to inform mitigation and (v) action higher up the 'plastics chain' closer to source, echoing calls for a coordinated approach to improve waste management strategies across Latin America ${ }^{65}$ and in international fisheries operating in the Eastern Pacific ${ }^{66}$.

\section{Declarations}

\section{Acknowledgements}

This study is part of the 'Plastic Pollution Free Galapagos' initiative; a multi-disciplinary, international research collaboration launched in 2018 and falls under the Galapagos Science Center's "Understanding the Effects of Marine Debris in the Galápagos" permit authorised by the Galápagos National Park Directorate (GNPD) (PC-44-18 and PC-23-19) granted to J.P.M.P.. We would like to thank administrative 
staff and students from the Galapagos Science Center for supporting data collection, particularly Arianna Torello, Kyle Oliveira, Kevin Cabrera, and also Captain Yuri Revelo from Yualka II. We thank the GNPD for the trust granted for sampling particularly to former San Cristóbal Technical Director Maryuri Yépez and the former GNPD Director Jorge Carrión Tacuri. Funding was provided to J.J. by the Galapagos Conservation Trust and the Woodspring Trust, a Ralph Brown Expedition grant from the Royal Geographical Society to C.L. supported fieldwork costs, a NERC Impact Award and a Global Challenges Research Fund Networking Grant supported T.G. in addition to National Environment Research Council grant NE/S003975/1 that also supported C.L. and A.P.

\section{Contributions}

J.J., A.P., C.L., J.P.M.P. and D.A.R. undertook the field sampling campaign and research permits and field logistics were provided by J.P.M.P. and D.A.R.. T.G. and B.G. advised on project design and analysis throughout. D.S. supported FT-IR analysis and training and J.V. supported risk scoring analysis. J.J, C.L., B.G., A.P. and T.G. wrote the main manuscript text, J.J. produced the figures, and all authors reviewed the manuscript.

\section{Methods}

\section{Study Site}

San Cristobal Island $\left(00^{\circ} 54^{\prime} 5.501 \mathrm{~S}, 89^{\circ} 36^{\prime} 47.537 \mathrm{~W}\right)$ is located in the east of the Galapagos Archipelago. The coastline is multi-use with a harbour town (population approx. 8,000), popular tourist and fishing sites as well as remote areas that have no public access. The eastern coast is characterised by high energy rocky reef coastline interspersed with small sandy bays, primarily comprised of biogenic sediments e.g. urchin tests. Conversely, the western coastline is more sheltered and characterised by finer sandy beaches and mangroves.

\section{Field Sampling \& Sample Processing}

Seventeen sites were selected around the coast of San Cristobal Island with two usage types: (i) tourist sites and (ii) remote (unvisited) areas with varying beach aspect (north/west, south, east). To gain a holistic understanding of plastic contamination, surveys were conducted for: (i) 
beach macroplastic, (ii) beach large microplastic (1 - $5 \mathrm{~mm}$ ), (iii) beach sediment (whole sand samples), (iv) seawater surface and (v) benthic sediment. Environmental sampling took place in May 2018 working from a small local fishing boat doing daily excursions from Puerto Baquerizo Moreno.

\section{Beach plastic surveys}

\section{a. Macroplastic}

To control for variable beach morphology and patchy plastic accumulation, 2 x $50 \mathrm{~m}$ macroplastic transects were sampled to generate representative data for the whole beach. All visible plastic items and fragments $(>5 \mathrm{~mm}$ ) between the waterline and vegetation line were removed, counted and categorised according to possible source using a modified OSPAR $\operatorname{protocol}^{21,67}$, see Supplementary Table 2 for categories. Beach area was calculated using satellite images (retrieved from Google Earth, January 2020) to convert data into items per square metre. A sub-sample of items from each location was taken for FTIR analysis to test for polymer similarity to smaller particle contamination ( $n=137$, approx. $5 \%$ of total sample).

\section{b. Large microplastics}

Large microplastics $(1-5 \mathrm{~mm}$ ) were collected by sieving the top $5 \mathrm{~cm}$ of sand from five $50 \mathrm{~cm}$ $\mathrm{x} 50 \mathrm{~cm}$ quadrats at least $5 \mathrm{~m}$ apart on the strandline of each beach spread between the two macroplastic transects. Stacked $5 \mathrm{~mm}$ and $1 \mathrm{~mm}$ sieves were submerged in a bucket of seawater to ease sieving and cause most plastic particles to float. Suspected plastics were collected by hand or using forceps and stored in a $50 \mathrm{~mL}$ centrifuge tube. Seawater was checked for any floating particles before use. We acknowledge that this method will likely underestimate the amounts of plastic in this size fraction but it represents a viable ongoing monitoring methodology, appropriate for citizen science (e.g. ${ }^{27}$ ). Falcon tubes containing the suspected plastics were washed out three times with deionised water and set out on filter 
papers for subsequent analysis. Particles $<1 \mathrm{~mm}$ were discounted to ensure data was quantitative.

\section{c. Microplastic and synthetic particles in beach sand}

Due to their artificial composition and poor understanding of biological impacts, we have included anthropogenically modified cellulosic polymers (e.g. rayon, viscose) in our counts as per Hartmann et al. ${ }^{68}$. To sample the smaller size fraction of beach plastic, triplicate $50 \mathrm{~mL}$ sand 'cores' were collected using centrifuge tubes at the strandline within the macroplastic transects. Sand samples were processed according to the density floatation protocol outlined by Coppock et al., $2017^{69}$ with $50 \mathrm{~g}$ dry weight sediment suspended in a filtered zinc chloride $\left(\mathrm{ZnCl}_{2}\right)$ solution with a density of $1.5 \mathrm{~g} \mathrm{~cm}^{-3}$ causing the majority of polymers to float in a custom-made Sediment-Microplastic Isolation unit. The surface compartment was poured off and filtered through $10 \mu \mathrm{m}$ polycarbonate filters. Grain size was measured using a Saturn Digisizer using $2 \mathrm{~g}$ samples previously sieved to $1 \mathrm{~mm}$ and digested for 24 hours in $\mathrm{H}_{2} \mathrm{O}_{2}$ solution.

\section{Seawater surface sampling}

Seawater surface tows of $2-10$ minutes at 2 knots boat speed were undertaken in triplicate using a $200 \mu \mathrm{m}$ plankton net with a flow meter, towing into the wind, away from the shoreline starting approx. $20 \mathrm{~m}$ offshore. GPS readings were taken at start and end of each tow. Samples were fixed in $4 \%$ formaldehyde solution in $500 \mathrm{~mL}$ Nalgene bottles. In sterile laboratory conditions, the formaldehyde solution was poured off through a $50 \mu \mathrm{m}$ white nylon mesh which was retained for inspection in a sealed petri dish. Approximately $100 \mathrm{~mL}$ of $20 \%$ filtered potassium hydroxide $(\mathrm{KOH})$ solution was added to the remaining plankton/ algae and they were shaken vigorously and heated at $40^{\circ} \mathrm{C}$ for 48 hours. Samples were shaken after addition of $\mathrm{KOH}$, after 24 hours and after 48 hours. Samples were filtered through $50 \mu \mathrm{m}$ nylon mesh 
and any remaining organic material was smeared on an extra mesh and sealed in petri dishes for later inspection.

\section{Benthic sediment sampling}

Benthic sediment samples were collected in triplicate taking a $50 \mathrm{~mL}$ sample from a $250 \mathrm{~cm}^{3}$ Van Veen Grab at 3 - 9 m depth at the finishing GPS position of the final seawater tow (approximately $20 \mathrm{~m}$ offshore). Benthic samples were processed following the same method as beach sand.

\section{Invertebrates}

Marine invertebrates were collected by hand in May 2018 and April 2019 during snorkelling, off rocks or on plastic litter found in the littoral zone and were thoroughly washed before freezing to minimise external contamination. In the lab, invertebrates were defrosted, measured (length) and dissected to remove soft tissues or just the digestive tract in the case of sea cucumbers, under clean conditions in a laminar flow fume hood and transferred to falcon tubes for oven-drying at $60^{\circ} \mathrm{C}$ overnight, with blanks. Dry weight was recorded and samples were digested with $30 \% \mathrm{KOH}$ solution at $40^{\circ} \mathrm{C}$ for 48 hours with shaking every 24 hours. Samples were filtered through $10 \mu \mathrm{m}$ polycarbonate filters (Whatman Nucleopore Hydrophilic Membrane).

\section{Contamination Control}

In the field, the plankton net was deployed suspended on a beam around $3 \mathrm{~m}$ off the side to minimise boat-based contamination blowing into the net. All kit was thoroughly cleaned between replicates and procedural blanks were undertaken in the field where possible. Nitrile gloves and cotton clothing were worn in the field and laboratory. In the lab, all surfaces and 
equipment were thoroughly cleaned down with ethanol (three times) or rinsed with Milli-Q (three times) before each processing step. Sterile plastic equipment was used directly from packaging and metal and glass materials were used in favour of plastics where possible and feasible. All samples and equipment were covered whenever possible by aluminium foil. Potential airbourne contamination was controlled for by leaving exposed dampened glass fibre filters both on the boat and in the lab during any sampling and procedural steps.

\section{Particle Composition \& FTIR Analysis}

Filters from environmental and organism samples were systematically examined using an Olympus MVX10 microscope and suspected synthetic particles were isolated, imaged, counted and categorized according to shape (fibre, fragment, foam, film, pellet) and colour. Particles were measured using Image J (length for fibres, feret diameter for all other particles types).

Particles were analysed using a PerkinElmer Frontier Fourier-transform infrared (FTIR) spectrometer using the attenuated total reflection (-ATR) universal diamond attachment for particles $>1 \mathrm{~mm}$ or a PerkinElmer Spotlight $400 \mu$ FT-IR Imaging System (MCT detector, $\mathrm{KBr}$ window) for particles $<1 \mathrm{~mm}$. Particles were transferred onto a Sterlitech $5.0 \mu \mathrm{m}$ silver membrane filter for analysis in reflectance mode (wavenumber resolution $4 \mathrm{~cm}^{-1}, 16$ scans, range from 4000 to $650 \mathrm{~cm}^{-1}$ ). Some fibres were isolated in a diamond anvil for analysis in transmission mode to improve spectra resolution. Normalisation and base-line correction tools from the Perkin-Elmer's Spectrum ${ }^{\mathrm{TM}} 10$ software (version 10.5.4.738) were used to further refine spectra. We used a general threshold of 70\% library match for FTIR polymer analysis, along with a strong visual sprectra match to improve our confidence in results. For strong visual matches with good quality spectra, we also accepted matches over $60 \%$ for invertebrates to allow for the possible effects of particle degradation by the organism or during sample digestion. 
Each of the procedural and atmospheric blanks underwent the same processing steps. Contamination was low but measurable, in seawater samples, 3 out of 12 atmospheric blanks had one black cellulosic fibre and 1 out of 12 had two fibres, one black, one blue cellulosic. In beach and benthic sediment samples, 1 out of 8 atmospheric blanks had a black polyester fibre and 7 out of 14 procedural blanks had 1 blue polyacrylamide or cellulosic fibre recovered. No contamination was recorded during processing of invertebrate samples (blanks $=8$ ). To control for this, the mean number for each particle category across all the blanks was subtracted from all data prior to further analysis and is not included in any data presented.

Of the 177 suspected synthetic particles, 50\% (89 particles) were disregarded after FTIR analysis due to identification as natural polymers or weak library spectral matches $(<60 \%)$, which is much higher than the rejection rate in particles extracted from environmental media $(<10 \%)$. This suggests that particle identification and isolation is more challenging in organisms, possibly due to transformations that organismal gut fluids and feeding mechanisms may have exerted on the particles, the additional methodological digestion steps and that particles are generally smaller.

\section{Threat-Scoring}

Species lists for marine vertebrates and invertebrates and information on the distribution and origin of species were retrieved from the Charles Darwin Research Station Natural History Collections database collated from sightings over several decades in Galapagos (https://www.darwinfoundation.org/en/datazone). The IUCN Red List status of each species was retrieved from the IUCN database (https://www.iucnredlist.org/). A database of available literature on marine plastic interaction through either entanglement or ingestion, was established using a systematic search process using Web of Science and other online search engines, yielding 319 articles to be included in the threat storing as demonstrating evidence of harm of plastic pollution in relevant species for the Galapagos marine food web. 


\section{a. Measurements of risk from plastics}

The species distribution, IUCN Red List status and both entanglement and ingestion literature statuses were each given unique scoring criteria. These scores were multiplied to give an overall risk score of plastic ingestion and entanglement for each species. The species distribution was grouped into five criteria: invasive, unknown, migratory, native and endemic and the seven categories used by the IUCN Red List to describe conservation status were allocated a score (Supplementary Table 5). The literature evidence for each species was first separated into entanglement and ingestion related publications, then organised into three categories describing the amount of evidence available surrounding the species interaction with plastic, considering the volume of published literature, the age of the material, the study design and scope. Categories were: No Evidence (1), Moderate (2) i.e. the species or a closely related species has had interactions that have resulted in non-lethal harm effects and Major (3) i.e. multiple sources of evidence that demonstrate this species has had major interactions with plastics resulting in severe injury and/or mortality.

Where there was insufficient research on the interaction of a species with plastics, comparisons were made using published information on species in the same taxonomic family. These species were allocated a maximum score of "2" (moderate) as they are likely to interact with marine plastics in a similar way as the closely related species, yet there is currently no evidence on the species and thus a score of " 3 " (major) is unjustifiable. The only exception to this rule was in the case of the marine iguana (Amblyrynchus cristatus) as they are the only marine iguana species on earth. Therefore, the evidence gathered on marine turtle species was used as a comparison as they are also marine herbivorous reptiles native to the region, and thus are likely to have experienced similar interactions with marine plastics. Annelids, arthropods, bryozoans, ctenophores, molluscs and several zooplankton groups were assessed but not included in the results presented due to low scores (all spp. $<4$ ). 
Calculation of threat from marine plastics entanglement and ingestion scores:

$$
\begin{aligned}
& S^{T E}=S^{D} \times S^{R} \times S^{E L} \\
& S^{T I}=S^{D} \times S^{R} \times S^{I L}
\end{aligned}
$$

The final score for species risk of entanglement was calculated using Eqn. 1, where $\mathrm{S}^{T E}$ is the final plastic entanglement risk score, $\mathrm{S}^{D}$ is the species distribution score, $\mathrm{S}^{R}$ is the IUCN Red List score and $\mathrm{S}^{E L}$ is the entanglement literature score. The final score for ingestion risk was calculated using Eqn. 2, where $\mathrm{S}^{T I}$ is the final plastic ingestion risk score, $\mathrm{S}^{D}$ is the species distribution score, $\mathrm{S}^{R}$ is the IUCN Red List score and $\mathrm{S}^{I L}$ is the ingestion literature score.

\section{Statistical Analyses}

All statistical analysis was undertaken in RStudio Version 1.1.463. All raw datasets were tested with a Shapiro-Wilk test for normality and Levene's test for homogeneity of variance and none met the requirements for parametric statistics. Differences in abundance were therefore statistically compared using a Kruskall-Wallis test with a post hoc Dunn's test to determine significant differences. Spearman's Rank Coefficient was used to test for correlation between abundances between habitats.

A negative binomial generalized linear model (GLM) was selected due to over-dispersed data and conducted for each response variable i.e. counts of (i) beach macroplastic, (ii) beach large microplastics, (iii) synthetic particles in whole sand samples, (iv) synthetic particles at the seawater surface and (v) synthetic particles in benthic sediments to identify the influence of environmental variables including beach aspect (north/west, south, east), windward vs leeward orientation, site usage (tourism, remote), distance from port and grain size. Optimisation was 
achieved by step-wise removal of the least significant variable (determined by the highest $p$ value) until the lowest Akaike Information Criterion (AIC) value was achieved and the fewest explanatory variables were identified. No interaction terms were included as they had a negligible effect on models. A dispersion test was undertaken to verify overdispersion of data. Top ranked models were defined as models $\Delta$ AIC $\leq 2$ units of the best supported model.

\section{References}

1. Lau, W. W. Y. et al. Evaluating scenarios toward zero plastic pollution. Science (80-). (2020).

2. Beaumont, N. J. et al. Global ecological, social and economic impacts of marine plastic. Mar. Pollut. Bull. 142, 189-195 (2019).

3. Tershy, B. R., Shen, K. W., Newton, K. M., Holmes, N. D. \& Croll, D. A. The importance of islands for the protection of biological and linguistic diversity. Bioscience 65, 592-597 (2015).

4. Lavers, J. L. \& Bond, A. L. Exceptional and rapid accumulation of anthropogenic debris on one of the world's most remote and pristine islands. Proc. Natl. Acad. Sci. 114, 6052-6055 (2017).

5. Rochman, C. M., Hoh, E., Hentschel, B. T. \& Kaye, S. Long-term field measurement of sorption of organic contaminants to five types of plastic pellets: Implications for plastic marine debris. Environ. Sci. Technol. 47, 1646-1654 (2013).

6. Bowley, J., Baker-austin, C., Porter, A. \& Hartnell, R. Oceanic Hitchhikers - Assessing Pathogen Risks from Marine Microplastic. Trends Microbiol. xx, 1-10 (2020).

7. Palacios, D. M. Seasonal patterns of sea-surface temperature and ocean color around the Galápagos: Regional and local influences. Deep. Res. Part II Top. Stud. Oceanogr. 51, 43-57 (2004).

8. Toral-Granda, M. V. et al. Alien species pathways to the Galapagos Islands, Ecuador. PLoS One 12, 121 (2017).

9. Walsh, S. J. \& Mena, C. F. Interactions of social, terrestrial, and marine sub-systems in the Galapagos Islands, Ecuador. Proc. Natl. Acad. Sci. 113, 14536-14543 (2016).

10. Carr, L. A. et al. Illegal shark fishing in the Galápagos Marine Reserve. Mar. Policy 39, 317-321 (2013).

11. Alava, J. J. et al. Polychlorinated Biphenyls and Polybrominated Diphenyl Ethers in Galapagos Sea Lions (Zalophus Wollebaeki). Environ. Toxicol. 28, 2271-2282 (2009).

12. Wikelski, M., Wong, V., Chevalier, B., Rattenborg, N. \& Snell, H. L. Marine iguanas die from trace oil pollution. Nature 417, 607-608 (2002).

13. Pizzitutti, F. et al. Scenario planning for tourism management: a participatory and system dynamics model applied to the Galapagos Islands of Ecuador. J. Sustain. Tour. 25, 1117-1137 (2017).

14. van Sebille, E. et al. Basin-scale sources and pathways of microplastic that ends up in the Galápagos Archipelago. Ocean Sci. Discuss. 1-15 (2019) doi:10.5194/os-2019-37. 
15. Jambeck, J. R. et al. Plastic waste inputs from land into the ocean. Science (80-.). 347, 768-771 (2015).

16. Schofield, J. et al. Object narratives as a methodology for mitigating marine plastic pollution: multidisciplinary investigations in Galápagos. Antiquity 94, 228-244 (2020).

17. Galloway, T. S., Cole, M. \& Lewis, C. Interactions of microplastic debris throughout the marine ecosystem. Nat. Ecol. Evol. 1, 1-8 (2017).

18. Stanton, T., Johnson, M., Nathanail, P., MacNaughtan, W. \& Gomes, R. L. Freshwater and airborne textile fibre populations are dominated by 'natural', not microplastic, fibres. Sci. Total Environ. 666, 377-389 (2019).

19. Andrady, A. L. Microplastics in the marine environment. Mar. Pollut. Bull. 62, 1596-1605 (2011).

20. Chubarenko, I., Efimova, I., Bagaeva, M., Bagaev, A. \& Isachenko, I. On mechanical fragmentation of single-use plastics in the sea swash zone with different types of bottom sediments: Insights from laboratory experiments. Mar. Pollut. Bull. 150, (2020).

21. Watts, A. J. R. et al. Through the sands of time: Beach litter trends from nine cleaned north cornish beaches. Environ. Pollut. 228, 416-424 (2017).

22. Mestanza, C. et al. Beach litter in Ecuador and the Galapagos islands: A baseline to enhance environmental conservation and sustainable beach tourism. Mar. Pollut. Bull. 140, 573-578 (2019).

23. Monteiro, R. C. P., Ivar do Sul, J. A. \& Costa, M. F. Plastic pollution in islands of the Atlantic Ocean. Environ. Pollut. 238, 103-110 (2018).

24. Gennip, S. J. van et al. In search for the sources of plastic marine litter that contaminates the Easter Island Ecoregion. Sci. Rep. 9, 1-13 (2019).

25. Boerder, K., Bryndum-Buchholz, A. \& Worm, B. Interactions of tuna fisheries with the Galápagos marine reserve. Mar. Ecol. Prog. Ser. 585, 1-15 (2017).

26. Ryan, P. G. \& Schofield, A. Low densities of macroplastic debris in the Pitcairn Islands Marine Reserve. Mar. Pollut. Bull. 157, (2020).

27. Hidalgo-Ruz, V. \& Thiel, M. Distribution and abundance of small plastic debris on beaches in the SE Pacific (Chile): A study supported by a citizen science project. Mar. Environ. Res. 87-88, 12-18 (2013).

28. PlasticsEurope. Plastics - the Facts 2017. https://www.plasticseurope.org/fr/resources/publications/plastics-facts2017\%0Ahttp://www.plasticseurope.org/ (2018) doi:10.1016/j.marpolbul.2013.01.015.

29. Scott, N. et al. Particle characteristics of microplastics contaminating the mussel Mytilus edulis and their surrounding environments. Mar. Pollut. Bull. 146, 125-133 (2019).

30. Zhang, H. Transport of microplastics in coastal seas. Estuar. Coast. Shelf Sci. 199, 74-86 (2017).

31. Wu, F. et al. Science of the Total Environment Accumulation of microplastics in typical commercial aquatic species: A case study at a productive aquaculture site in China. Sci. Total Environ. 708, 135432 (2020). 
32. Schwarz, A. E., Ligthart, T. N., Boukris, E. \& van Harmelen, T. Sources, transport, and accumulation of different types of plastic litter in aquatic environments: A review study. Mar. Pollut. Bull. 143, 92-100 (2019).

33. Welden, N. A. C. \& Cowie, P. R. Long-term microplastic retention causes reduced body condition in the langoustine, Nephrops norvegicus. Environ. Pollut. 218, 895-900 (2016).

34. Fang, C. et al. Microplastic contamination in benthic organisms from the Arctic and sub-Arctic regions. Chemosphere 209, 298-306 (2018).

35. Bour, A., Haarr, A., Keiter, S. \& Hylland, K. Environmentally relevant microplastic exposure affects sediment- dwelling bivalves *. Environ. Pollut. 236, 652-660 (2018).

36. Gutow, L., Eckerlebe, A., Giménez, L. \& Saborowski, R. Experimental Evaluation of Seaweeds as a Vector for Microplastics into Marine Food Webs. Environ. Sci. Technol. 50, 915-923 (2016).

37. Porter, A., Smith, K. E. \& Lewis, C. The sea urchin Paracentrotus lividus as a bioeroder of plastic. Sci. Total Environ. 693, 133621 (2019).

38. Renzi, M. et al. Chemical composition of microplastic in sediments and protected detritivores from different marine habitats (Salina Island). Mar. Pollut. Bull. 152, 110918 (2020).

39. Graham, E. R. \& Thompson, J. T. Deposit- and suspension-feeding sea cucumbers (Echinodermata) ingest plastic fragments. J. Exp. Mar. Bio. Ecol. 368, 22-29 (2009).

40. Wright, S. L., Thompson, R. C. \& Galloway, T. S. The physical impacts of microplastics on marine organisms: A review. Environ. Pollut. 178, 483-492 (2013).

41. Haegerbaeumer, A., Mueller, M.-T., Fueser, H. \& Traunspurger, W. Impacts of Micro- and Nano-Sized Plastic Particles on Benthic Invertebrates: A Literature Review and Gap Analysis. Front. Environ. Sci. 7. (2019).

42. Manzello, D. P. et al. Galápagos coral reef persistence after ENSO warming across an acidification gradient. Geophys. Res. Lett. 41, 9001-9008 (2014).

43. Okubo, N., Takahashi, S. \& Nakano, Y. Microplastics disturb the anthozoan-algae symbiotic relationship. Mar. Pollut. Bull. 135, 83-89 (2018).

44. Reichert, J., Schellenberg, J., Schubert, P. \& Wilke, T. Responses of reef building corals to microplastic exposure. Environ. Pollut. 237, 955-960 (2018).

45. Lamb, J. B. et al. Plastic waste associated with disease on coral reefs. Science (80-.). 359, 460-462 (2018).

46. Parton, K. J., Galloway, T. S. \& Godley, B. J. Global review of shark and ray entanglement in anthropogenic marine debris. Endanger. Species Res. 39, 173-190 (2019).

47. Thiel, M. et al. Impacts of Marine Plastic Pollution From Continental Coasts to Subtropical GyresFish, Seabirds, and Other Vertebrates in the SE Pacific. Front. Mar. Sci. 5, (2018).

48. Nunes, J. A. C. C., Sampaio, C. L. S., Barros, F. \& Leduc, A. O. H. C. Plastic debris collars: An underreported stressor in tropical reef fishes. Mar. Pollut. Bull. 129, 802-805 (2018). 
49. Nelms, S. E. et al. Plastic and marine turtles: A review and call for research. ICES J. Mar. Sci. 73, 165181 (2016).

50. Schuyler, Q. A. et al. Risk analysis reveals global hotspots for marine debris ingestion by sea turtles. Glob. Chang. Biol. 22, 567-576 (2016).

51. Wilcox, C., Puckridge, M., Schuyler, Q. A., Townsend, K. \& Hardesty, B. D. A quantitative analysis linking sea turtle mortality and plastic debris ingestion. Sci. Rep. 1-11 (2018) doi:10.1038/s41598018-30038-z.

52. Duncan, E. et al. Microplastic ingestion ubiquitous in marine turtles. Glob. Chang. Biol. 744-752 (2019) doi:10.1111/gcb.14519.

53. MacLeod, A., Cooke, S. C. \& Trillmich, F. The spatial ecology of invasive feral cats Felis catus on San Cristóbal, Galápagos: first insights from GPS collars. Mammal Res. 65, 621-628 (2020).

54. Wilcox, C., Van Sebille, E., Hardesty, B. D. \& Estes, J. A. Threat of plastic pollution to seabirds is global, pervasive, and increasing. Proc. Natl. Acad. Sci. U. S. A. 112, 11899-11904 (2015).

55. Ryan, P. G. How quickly do albatrosses and petrels digest plastic particles? Environ. Pollut. 207, 438440 (2015).

56. Brandão, M. L., Braga, K. M. \& Luque, J. L. Marine debris ingestion by Magellanic penguins, Spheniscus magellanicus (Aves: Sphenisciformes), from the Brazilian coastal zone. Mar. Pollut. Bull. 62, 2246-2249 (2011).

57. Donnelly-Greenan, E. L., Nevins, H. M. \& Harvey, J. T. Entangled seabird and marine mammal reports from citizen science surveys from coastal California (1997-2017). Mar. Pollut. Bull. 149, 110557 (2019).

58. Yorio, P., Marinao, C. \& Suárez, N. Kelp Gulls (Larus dominicanus) killed and injured by discarded monofilament lines at a marine recreational fishery in northern Patagonia. Mar. Pollut. Bull. 85, 186189 (2014).

59. Schiller, L., Alava, J. J., Grove, J., Reck, G. \& Pauly, D. The demise of Darwin's fishes: Evidence of fishing down and illegal shark finning in the Galápagos Islands. Aquat. Conserv. Mar. Freshw. Ecosyst. 25, 431-446 (2015).

60. Alava, J. J., Palomera, C., Bendell, L. \& Ross, P. S. Pollution as an Emerging Threat for the Conservation of the Galapagos Marine Reserve: Environmental Impacts and Management Perspectives. (Springer, 2014).

61. Denuncio, P. et al. Marine debris ingestion by the South American Fur Seal from the Southwest Atlantic Ocean. Mar. Pollut. Bull. 122, 420-425 (2017).

62. Goldstein, M. C., Carson, H. S. \& Eriksen, M. Relationship of diversity and habitat area in North Pacific plastic-associated rafting communities. Mar. Biol. 161, 1441-1453 (2014).

63. Edgar, G. J. et al. El Niño, grazers and fisheries interact to greatly elevate extinction risk for Galapagos marine species. Glob. Chang. Biol. 16, 2876-2890 (2010). 
64. Ruiz, D. J. \& Wolff, M. The Bolivar Channel Ecosystem of the Galapagos Marine Reserve: Energy flow structure and role of keystone groups. J. Sea Res. 66, 123-134 (2011).

65. Margallo, M. et al. Enhancing waste management strategies in Latin America under a holistic environmental assessment perspective: A review for policy support. Sci. Total Environ. 689, 12551275 (2019).

66. Richardson, K., Haynes, D., Talouli, A. \& Donoghue, M. Marine pollution originating from purse seine and longline fishing vessel operations in the Western and Central Pacific Ocean, 2003-2015. Ambio 46, 190-200 (2017).

67. OSPAR. Guideline for Monitoring Marine Litter on the Beaches in the OSPAR Maritime Area. OSPAR Commission, London. (2010).

68. Hartmann, N. B. et al. Are We Speaking the Same Language? Recommendations for a Definition and Categorization Framework for Plastic Debris. Environ. Sci. Technol. 53, 1039-1047 (2019).

69. Coppock, R. L., Cole, M., Lindeque, P. K., Queirós, A. M. \& Galloway, T. S. A small-scale, portable method for extracting microplastics from marine sediments. Environ. Pollut. 230, 829-837 (2017).

\section{Figures}

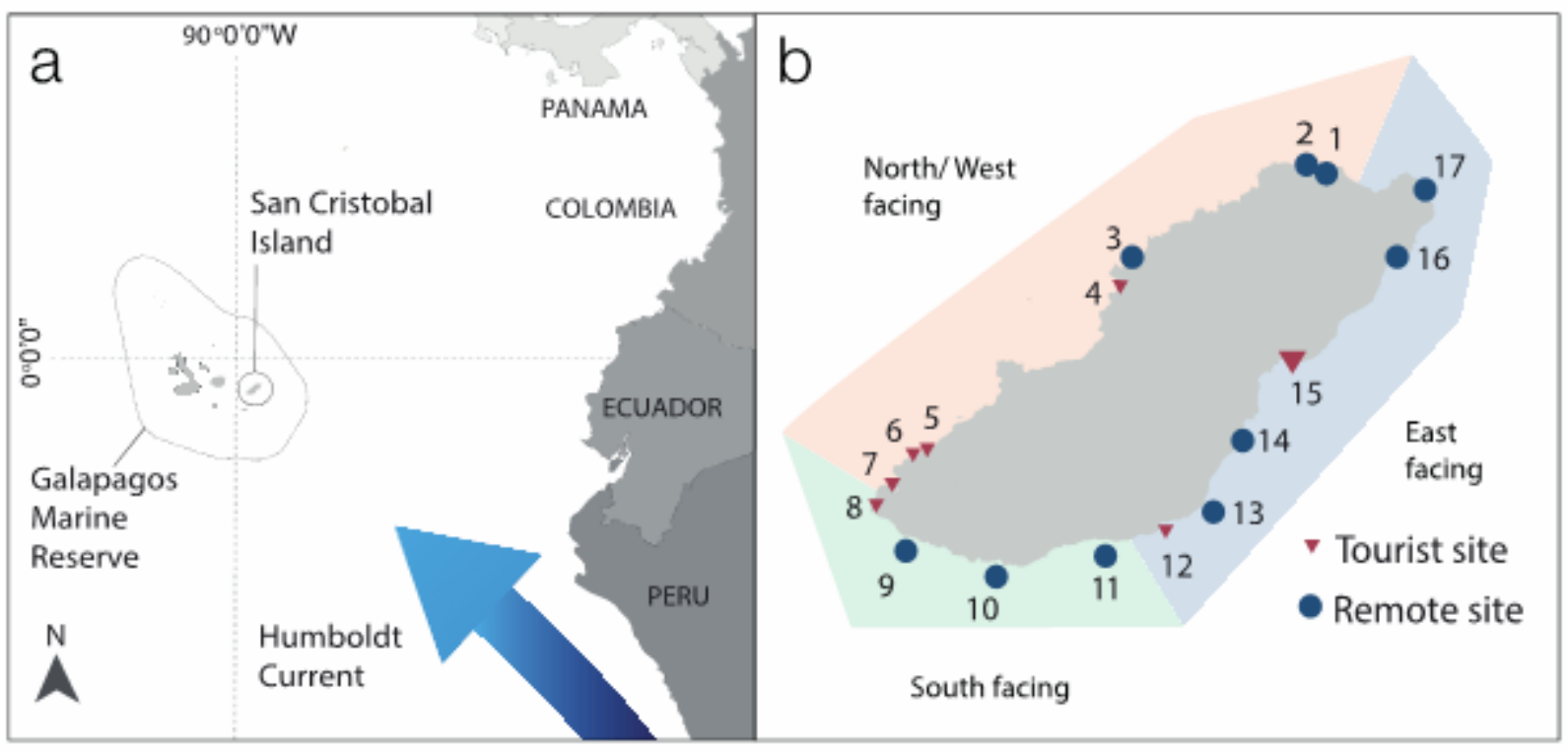

\section{Figure 1}

Geographic location of study site: San Cristobal Island, Galapagos, Ecuador. (a) Geographical location of San Cristobal Island in the Eastern Pacific Ocean showing the Humboldt Current and the limits of the protected Galapagos Marine Reserve; (b) study sites coded by type (tourist sites / remote sites) and the aspect of beaches (i.e. north or west facing (grouped together due to sample size and similarity), south facing or east facing). 


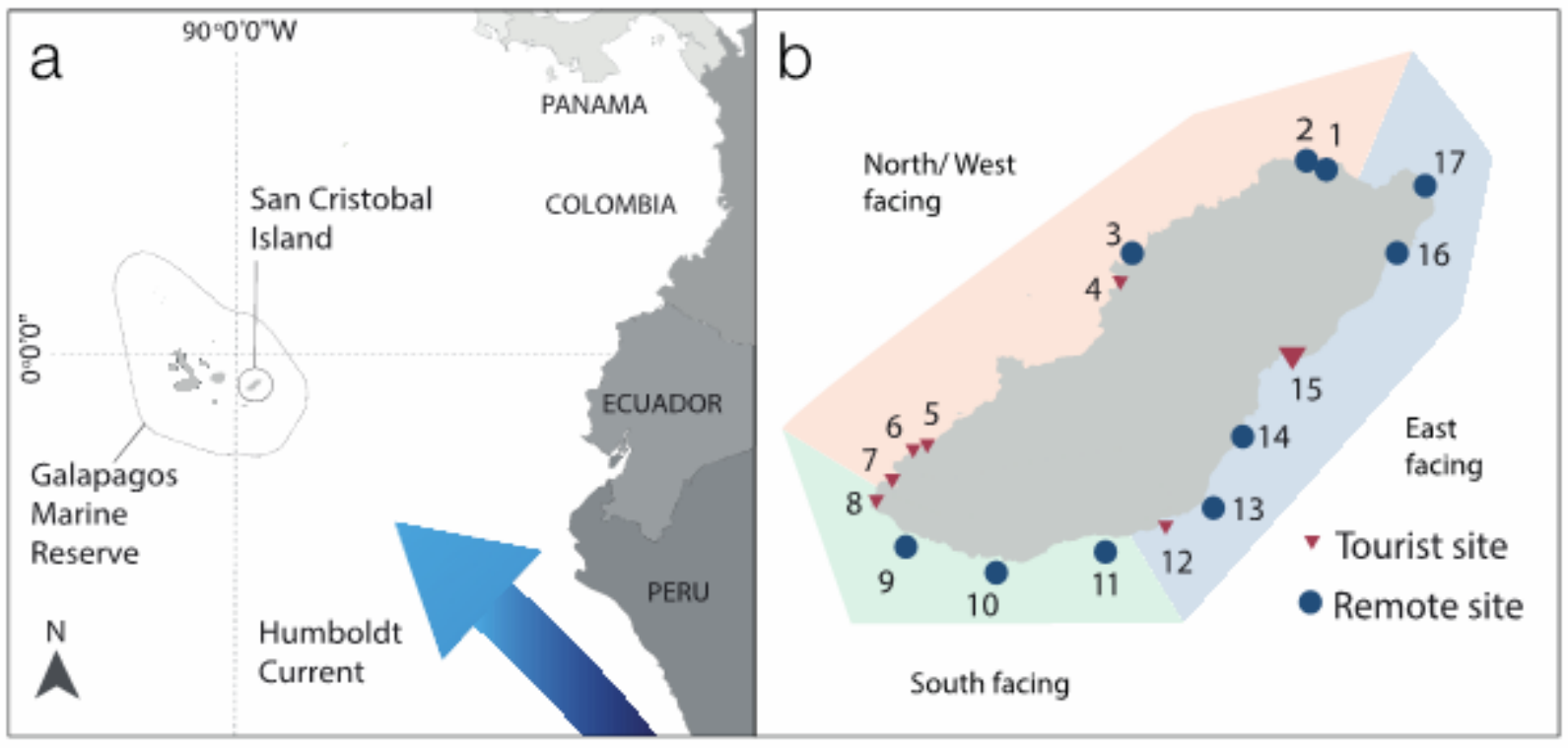

\section{Figure 1}

Geographic location of study site: San Cristobal Island, Galapagos, Ecuador. (a) Geographical location of San Cristobal Island in the Eastern Pacific Ocean showing the Humboldt Current and the limits of the protected Galapagos Marine Reserve; (b) study sites coded by type (tourist sites / remote sites) and the aspect of beaches (i.e. north or west facing (grouped together due to sample size and similarity), south facing or east facing).

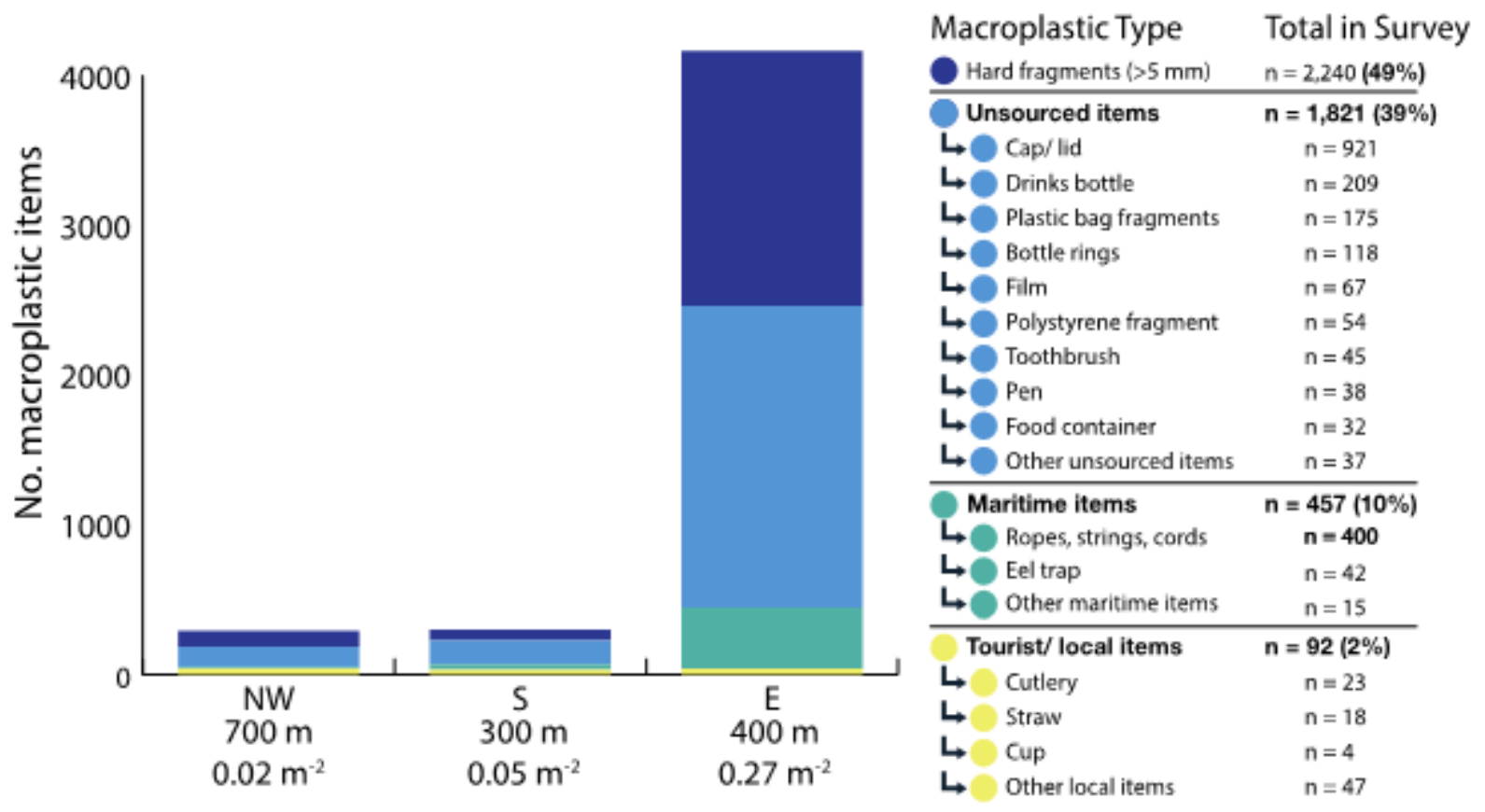

Figure 2

Composition of beach macroplastic found on San Cristobal Island, Galapagos, Ecuador. Items recovered from the beach surface across 14 north/west, south and east facing beaches with total distance 
surveyed $(m)$ and mean litter density ( $m-2)$ labelled for each group. Totals and percentage of each item source type are reported across the full $1.4 \mathrm{~km}$ surveyed coastline in the key along with a breakdown of major contributing items. A full list of categories is included in Supplementary Table 2.

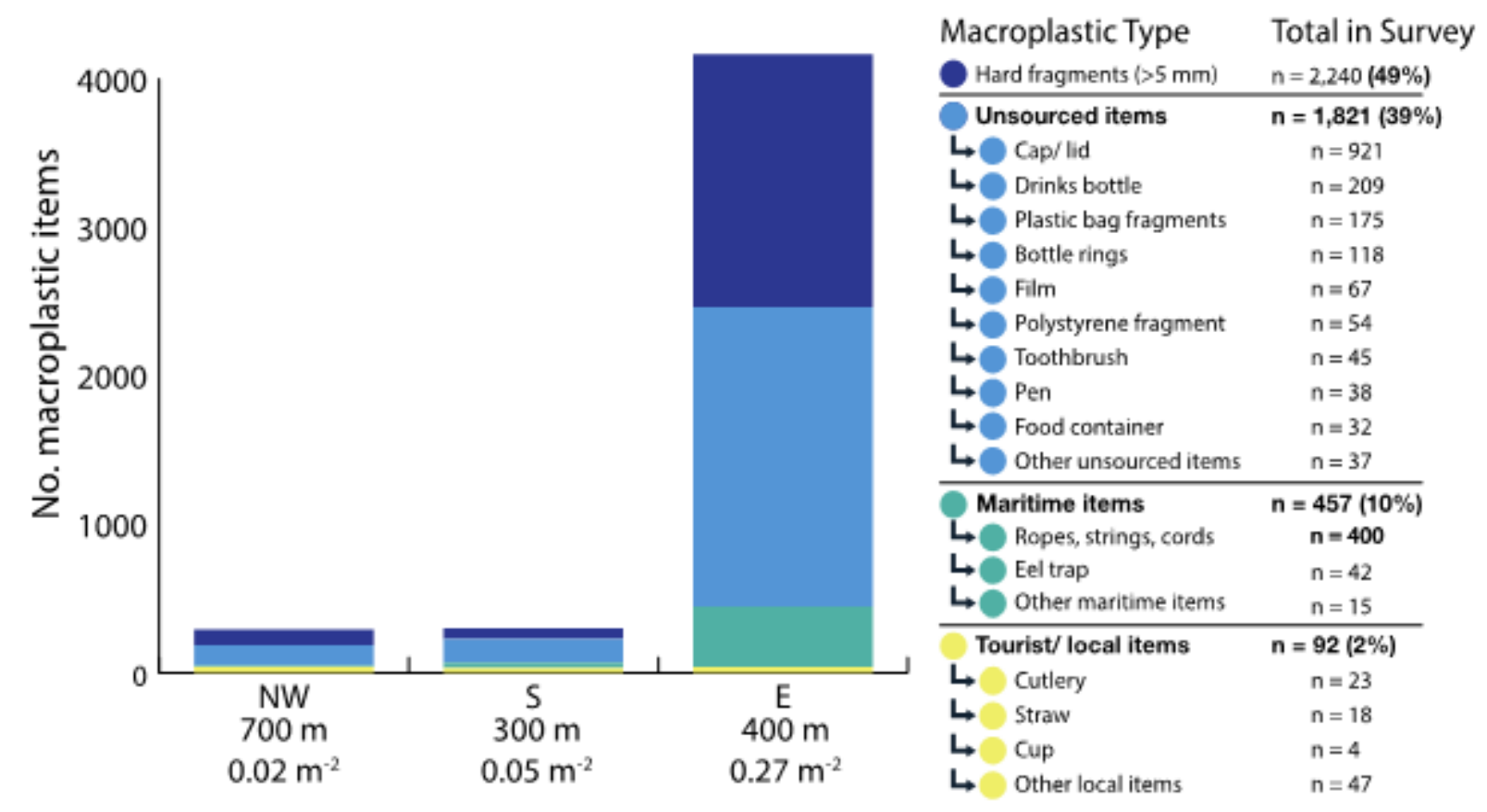

Figure 2

Composition of beach macroplastic found on San Cristobal Island, Galapagos, Ecuador. Items recovered from the beach surface across 14 north/west, south and east facing beaches with total distance surveyed $(m)$ and mean litter density $(m-2)$ labelled for each group. Totals and percentage of each item source type are reported across the full $1.4 \mathrm{~km}$ surveyed coastline in the key along with a breakdown of major contributing items. A full list of categories is included in Supplementary Table 2. 
a

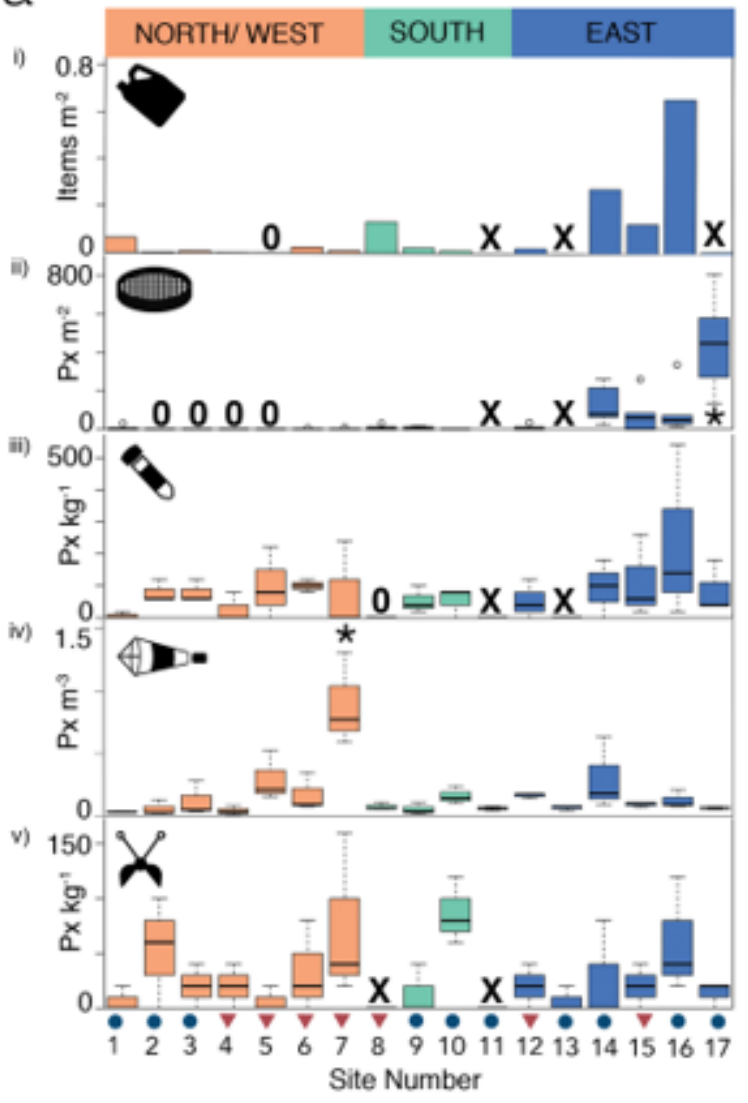

b
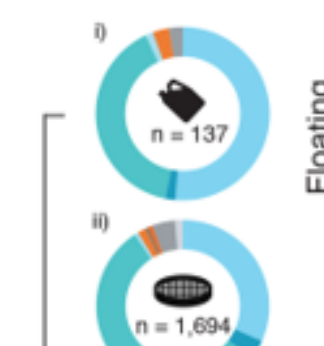

\section{ᄃ}

iii)

ii)

$=1,69$

8

$n=172$

w)

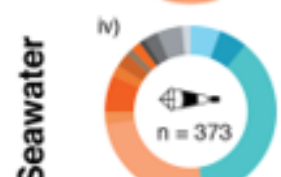

(ब)
Polymer Key

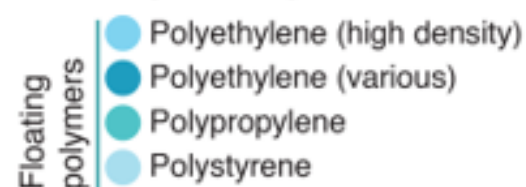

Cellulosic (synthetic)

Modacrylic

Nylon

Polyamide

Polyester

Polyvinyl chloride

Adhesive

Plasticizer

Polyacrylamide

Other plastics

Other synthetic polymers

\section{Figure 3}

Abundance and polymer composition of macroplastic items and synthetic particles (including microplastics) around San Cristobal Island, Galapagos, Ecuador. (a) Abundance of (i) beach surface macroplastic (items m-2); (ii) sieved large microplastics $(1-5 \mathrm{~mm}$ ) particles (hereby denoted by px) m-

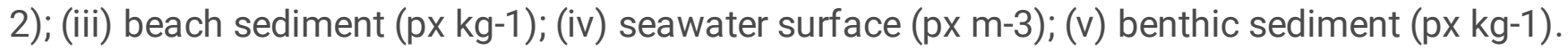

Significant values (Kruskall-Wallis Test with Dunn's Posthoc) indicated by asterisks. ' $X$ ' indicates sites where sampling was not possible for that habitat and zero values (0) are labelled. Sites are grouped by beach aspect (north/west, south or east) and labelled as remote sites (blue circles) and tourist sites (red triangles). (b) Polymer composition of macroplastic items and synthetic particles (denoted by $\mathrm{n}$ ) recovered from environmental samples as verified by Fourier Transform Infrared Spectroscopy (FTIR) for beach ( $\mathrm{i}$ - iii), seawater surface (iv) and benthic sediment (v). Polymers are labelled as floating (blue colours), sinking (orange colours) or unknown (grey). 
a

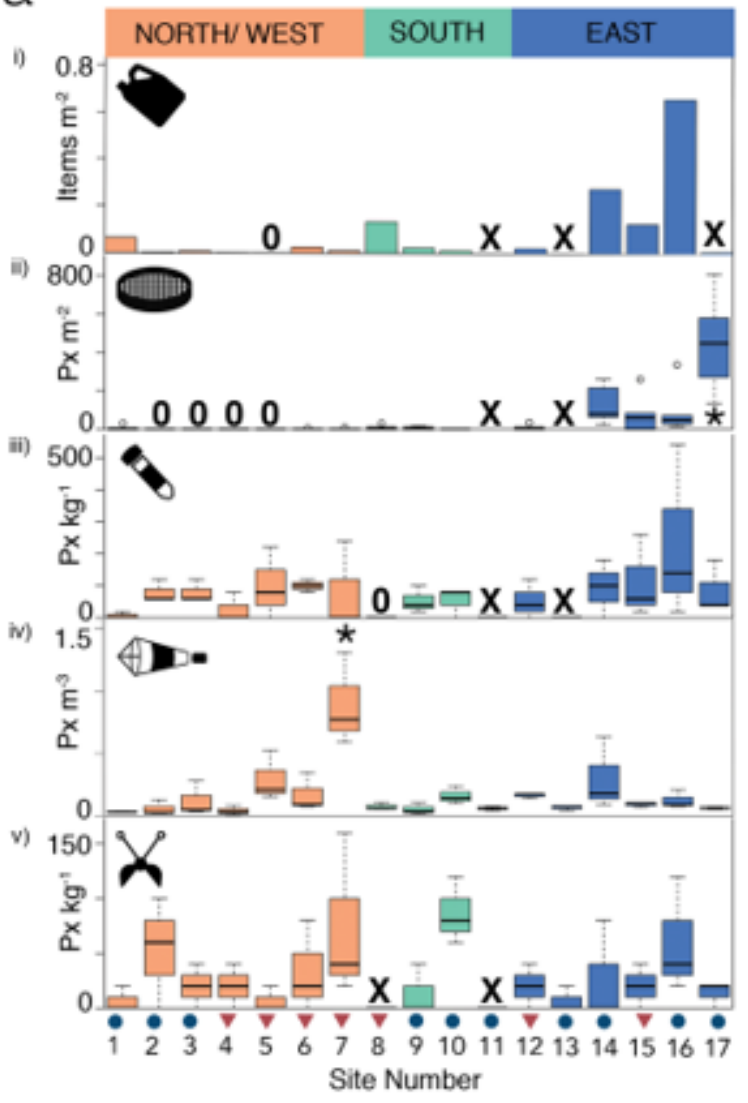

b
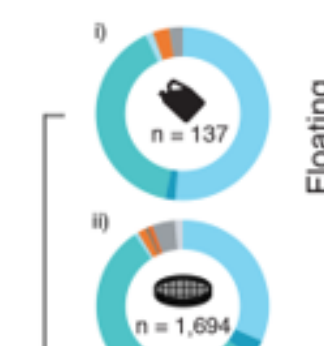

\section{ㄷ్ㅀ}

iii)

ii)

$=1,69$

8

$n=172$

w)

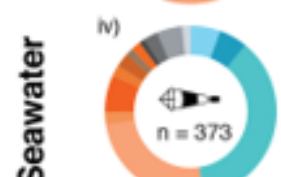

(ब)
Polymer Key

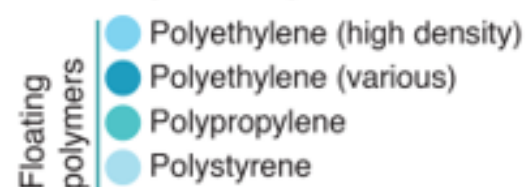

Cellulosic (synthetic)

Modacrylic

Nylon

Polyamide

Polyester

Polyvinyl chloride

Adhesive

Plasticizer

Polyacrylamide

Other plastics

Other synthetic polymers

\section{Figure 3}

Abundance and polymer composition of macroplastic items and synthetic particles (including microplastics) around San Cristobal Island, Galapagos, Ecuador. (a) Abundance of (i) beach surface macroplastic (items m-2); (ii) sieved large microplastics $(1-5 \mathrm{~mm}$ ) particles (hereby denoted by px) m-

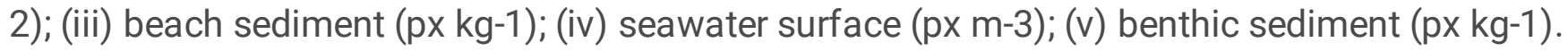

Significant values (Kruskall-Wallis Test with Dunn's Posthoc) indicated by asterisks. ' $X$ ' indicates sites where sampling was not possible for that habitat and zero values (0) are labelled. Sites are grouped by beach aspect (north/west, south or east) and labelled as remote sites (blue circles) and tourist sites (red triangles). (b) Polymer composition of macroplastic items and synthetic particles (denoted by $\mathrm{n}$ ) recovered from environmental samples as verified by Fourier Transform Infrared Spectroscopy (FTIR) for beach ( $\mathrm{i}$ - iii), seawater surface (iv) and benthic sediment (v). Polymers are labelled as floating (blue colours), sinking (orange colours) or unknown (grey). 


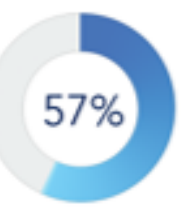

(i) Goose

Barnacles

$\mathrm{n}=7$

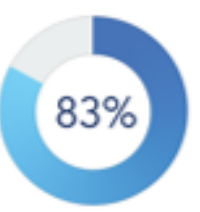

(ii) Giant

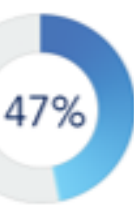

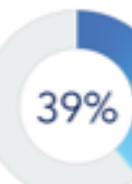

(iv) Nerite Snails

$\mathrm{n}=6$

$n=12$

$\mathrm{n}=23$ (v) Chitons

$\mathrm{n}=4$

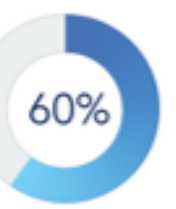

(vi) Pencil (vii) Sea Urchins

$\mathrm{n}=22$

\section{$55 \%$}

Cucumbers

$\mathrm{n}=49$

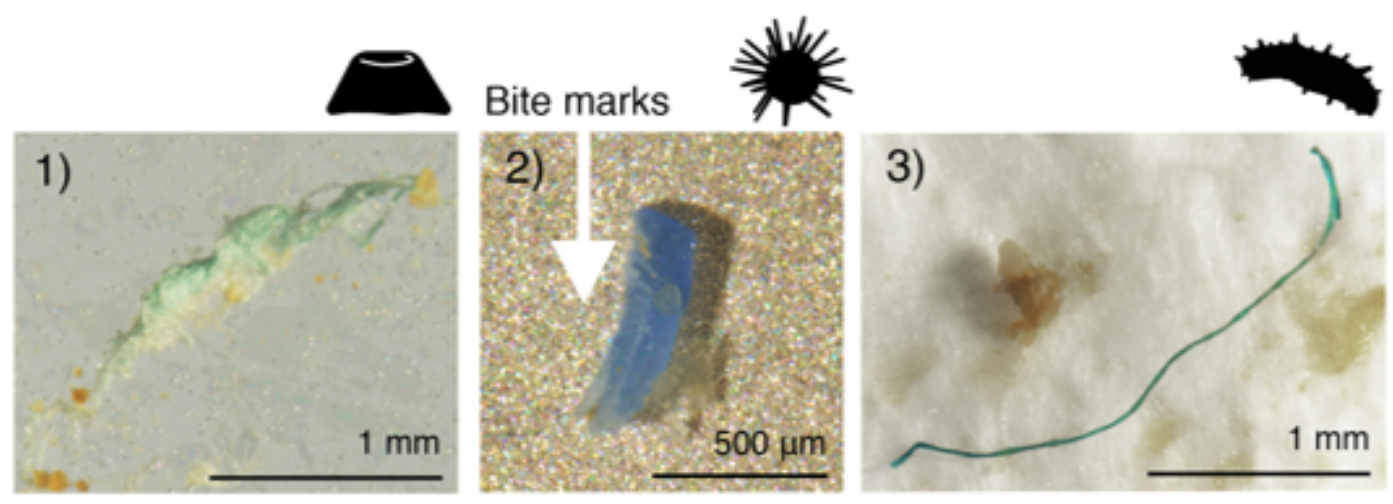

\section{Figure 4}

Synthetic particle uptake in marine invertebrates. Percentage of organisms containing synthetic particles (including petrochemical microplastics and highly modified anthropogenic cellulosics) and number of individuals sampled (n) across seven species: (i) goose barnacles (Lepas anatifera), (ii) giant barnacles (Megabalanus peninsularis), (iii) palmate oysters (Saccostrea palmula), (iv) rough-ribbed nerite snails (Nerita scabricosta), (v) sculptured chiton (Chiton sulcatus), (vi) slate pencil urchins (Eucidaris galapagensis), (vii) sea cucumber (Holothuria kefersteini); images of typical particles recovered: (1) a clump of green polypropylene fibres recovered from a goose barnacle, (2) a blue polypropylene fragment with suspected bite marks recovered from a slate pencil urchin and (3) a blue/green synthetic cellulosic fibre recovered from a sea cucumber. 


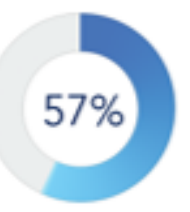

(i) Goose

Barnacles

$\mathrm{n}=7$

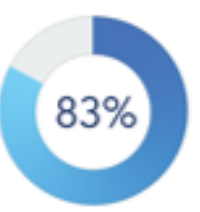

(ii) Giant

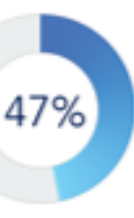

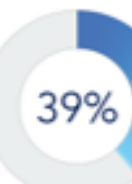

(iv) Nerite Snails

$\mathrm{n}=6$

$n=12$

$\mathrm{n}=23$ (v) Chitons

$\mathrm{n}=4$

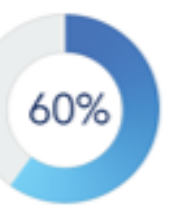

(vi) Pencil (vii) Sea Urchins

$\mathrm{n}=22$

\section{$55 \%$}

Cucumbers

$\mathrm{n}=49$

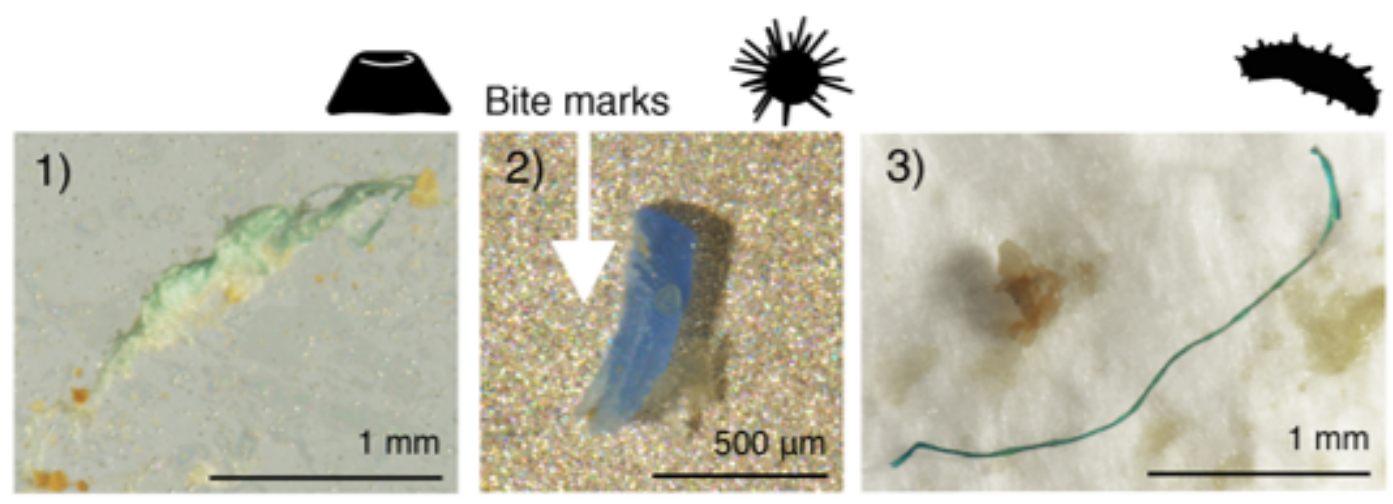

\section{Figure 4}

Synthetic particle uptake in marine invertebrates. Percentage of organisms containing synthetic particles (including petrochemical microplastics and highly modified anthropogenic cellulosics) and number of individuals sampled (n) across seven species: (i) goose barnacles (Lepas anatifera), (ii) giant barnacles (Megabalanus peninsularis), (iii) palmate oysters (Saccostrea palmula), (iv) rough-ribbed nerite snails (Nerita scabricosta), (v) sculptured chiton (Chiton sulcatus), (vi) slate pencil urchins (Eucidaris galapagensis), (vii) sea cucumber (Holothuria kefersteini); images of typical particles recovered: (1) a clump of green polypropylene fibres recovered from a goose barnacle, (2) a blue polypropylene fragment with suspected bite marks recovered from a slate pencil urchin and (3) a blue/green synthetic cellulosic fibre recovered from a sea cucumber. 

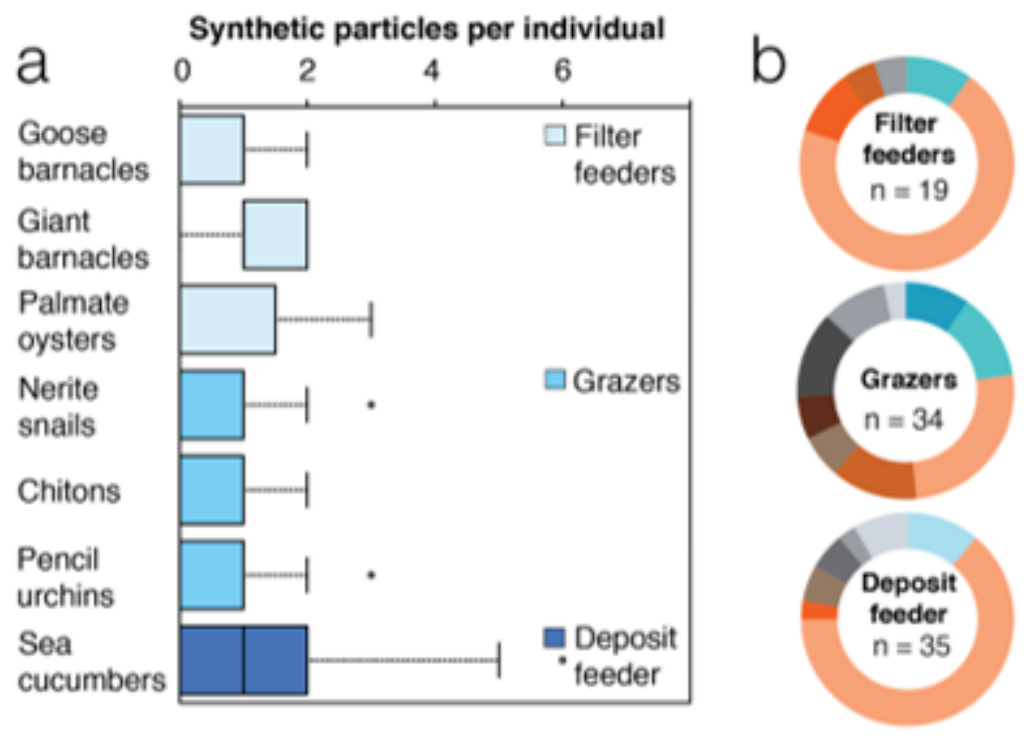

Polymer Key

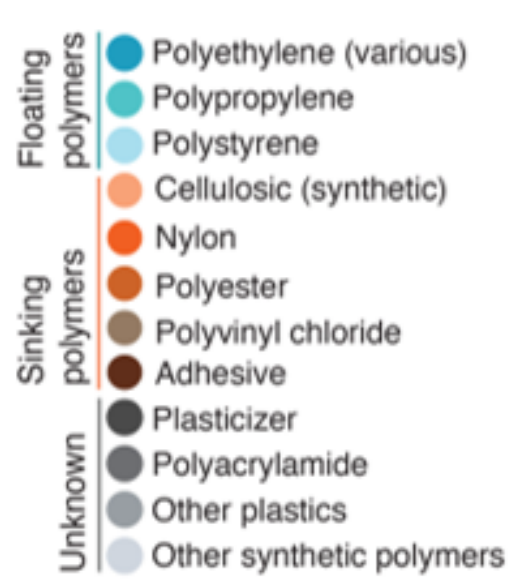

\section{Figure 5}

Synthetic particle abundance and composition in marine invertebrates. (a) Mean synthetic particles per individual averaged over all sampled species grouped by feeding mode; (b) Polymer composition of particles (denoted by $\mathrm{n}$ ) extracted from filter feeders, grazers and surface deposit feeders.
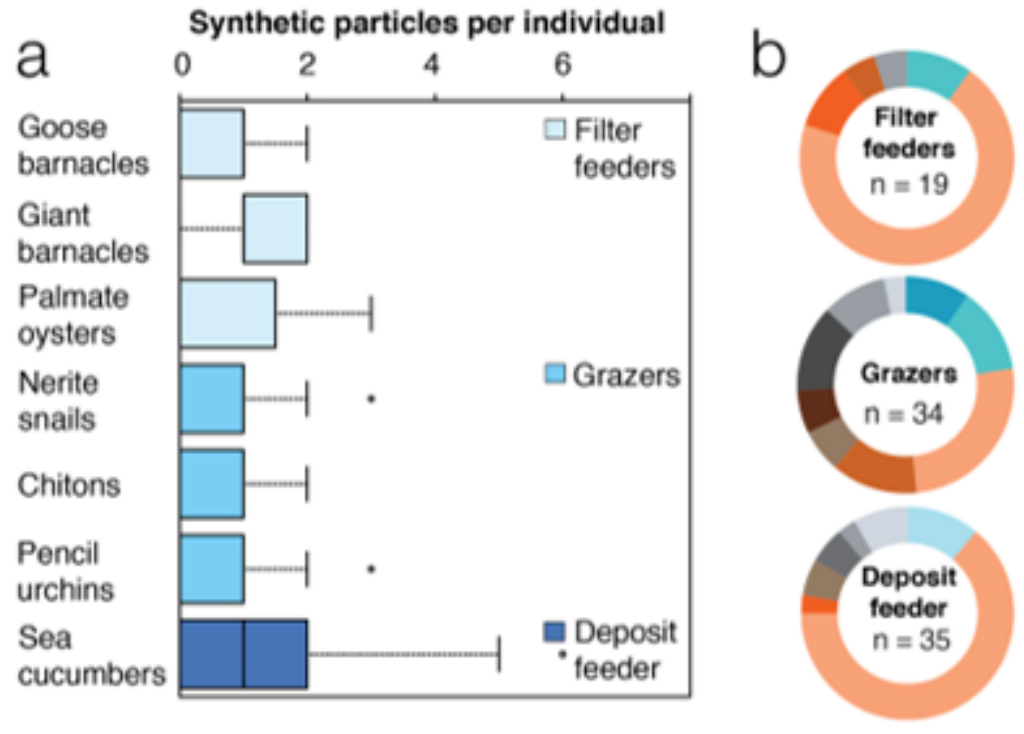

\section{Polymer Koy}

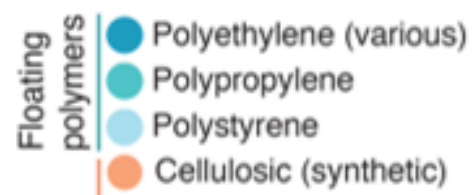

in Nylon

它

Polyvinyl chloride

ॐ \&. Adhesive

Plasticizer

Polyacrylamide

Other plastics

Other synthetic polymers

\section{Figure 5}

Synthetic particle abundance and composition in marine invertebrates. (a) Mean synthetic particles per individual averaged over all sampled species grouped by feeding mode; (b) Polymer composition of particles (denoted by n) extracted from filter feeders, grazers and surface deposit feeders. 


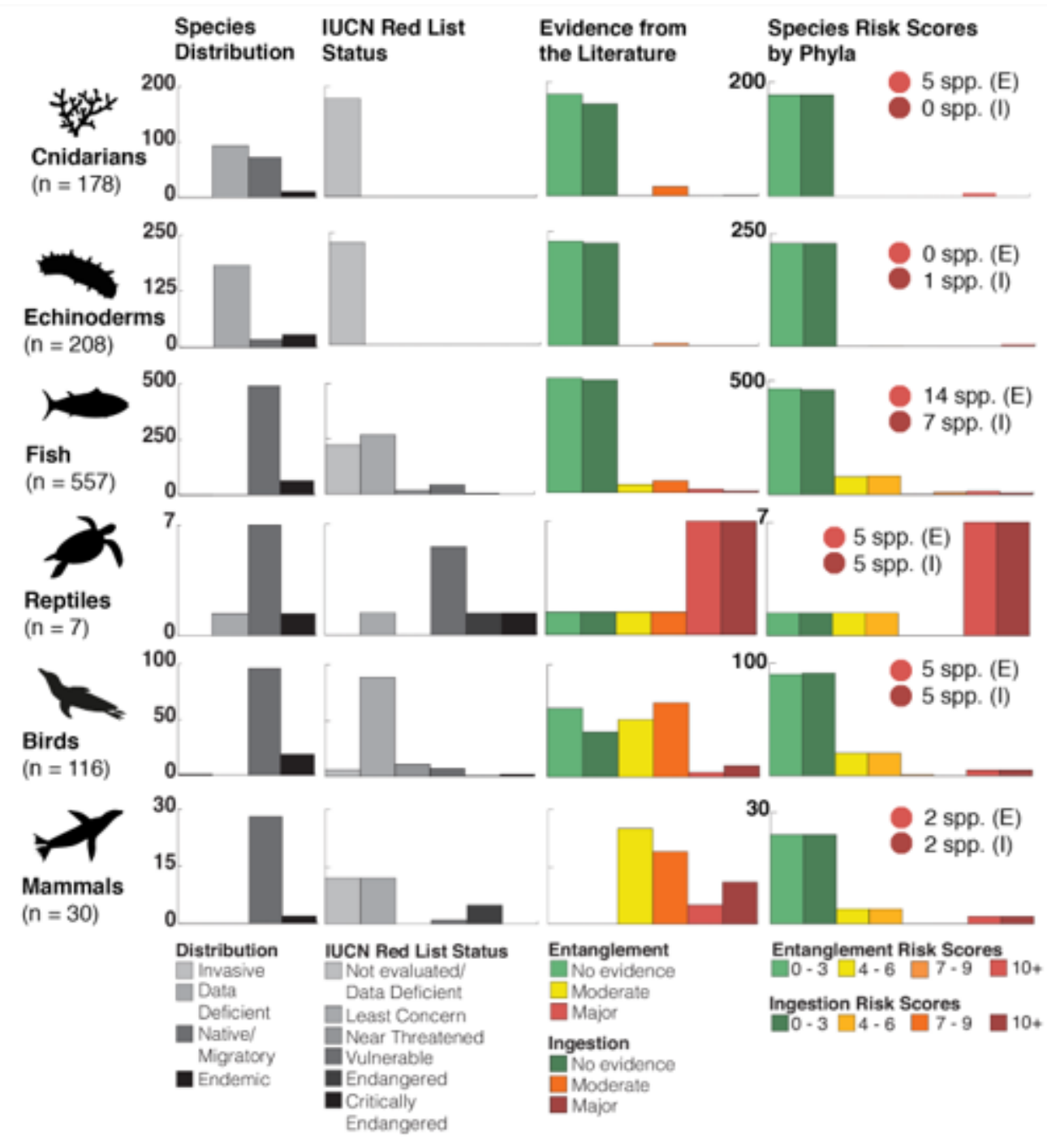

Figure 6

Summary of risk scoring analysis for Galapagos marine species and plastic pollution. Scoring elements include species distribution, IUCN Red List status and evidence from the literature for harm from plastic pollution caused by entanglement and ingestion at a taxonomic family level. Each element was scored ( 0 - 3) and combined to give a final risk score, shown distributed across species within each group in the final column. As numbers in species groups varied from 7 to 557 , numbers of species scoring $10+$ (severe) for either entanglement and/or ingestion are listed next to red circles for each group resulting in a list of 32 priority species (see Supplementary Table 6 for species list). 


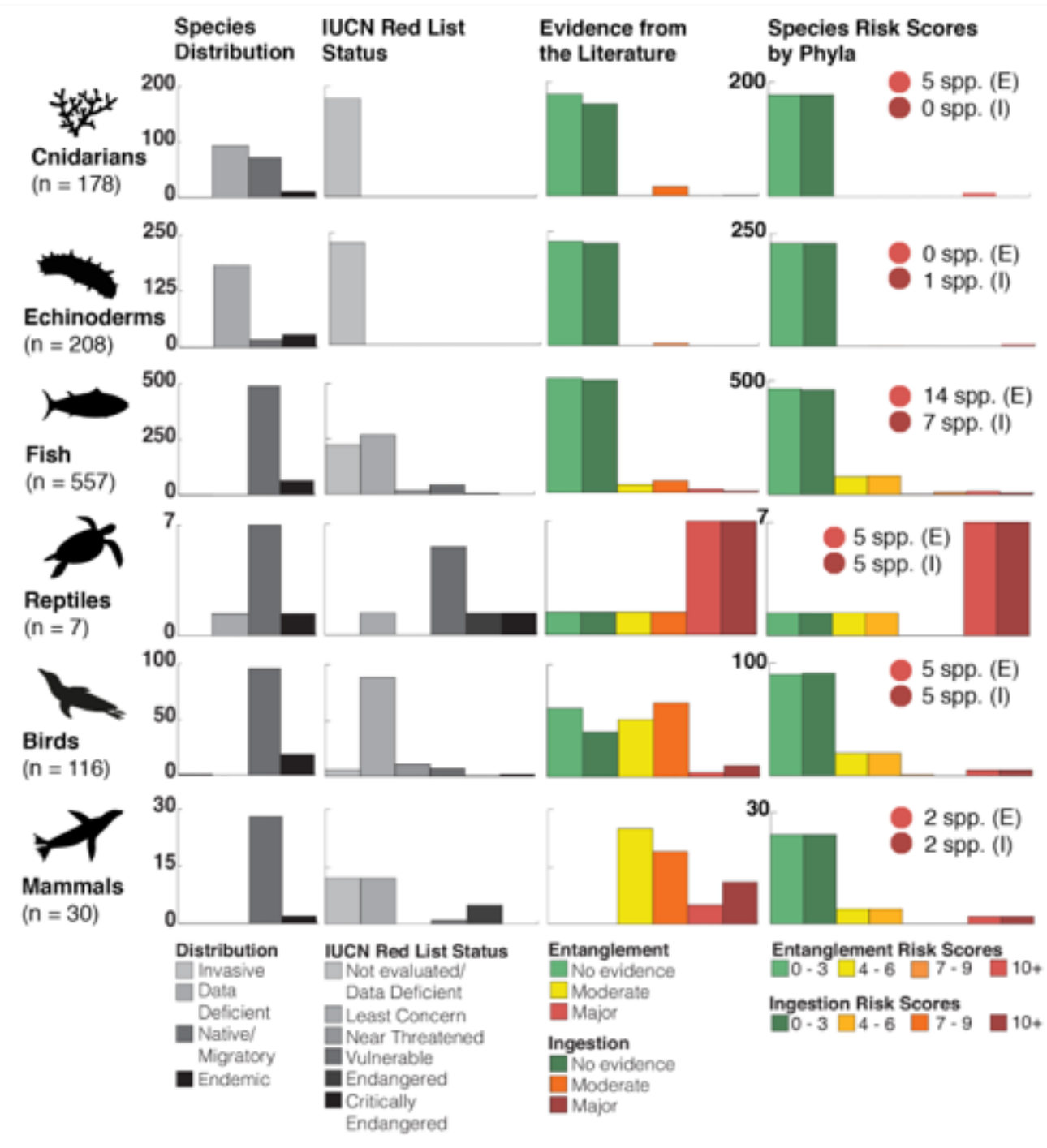

Figure 6

Summary of risk scoring analysis for Galapagos marine species and plastic pollution. Scoring elements include species distribution, IUCN Red List status and evidence from the literature for harm from plastic pollution caused by entanglement and ingestion at a taxonomic family level. Each element was scored ( 0 - 3) and combined to give a final risk score, shown distributed across species within each group in the final column. As numbers in species groups varied from 7 to 557 , numbers of species scoring $10+$ (severe) for either entanglement and/or ingestion are listed next to red circles for each group resulting in a list of 32 priority species (see Supplementary Table 6 for species list). 


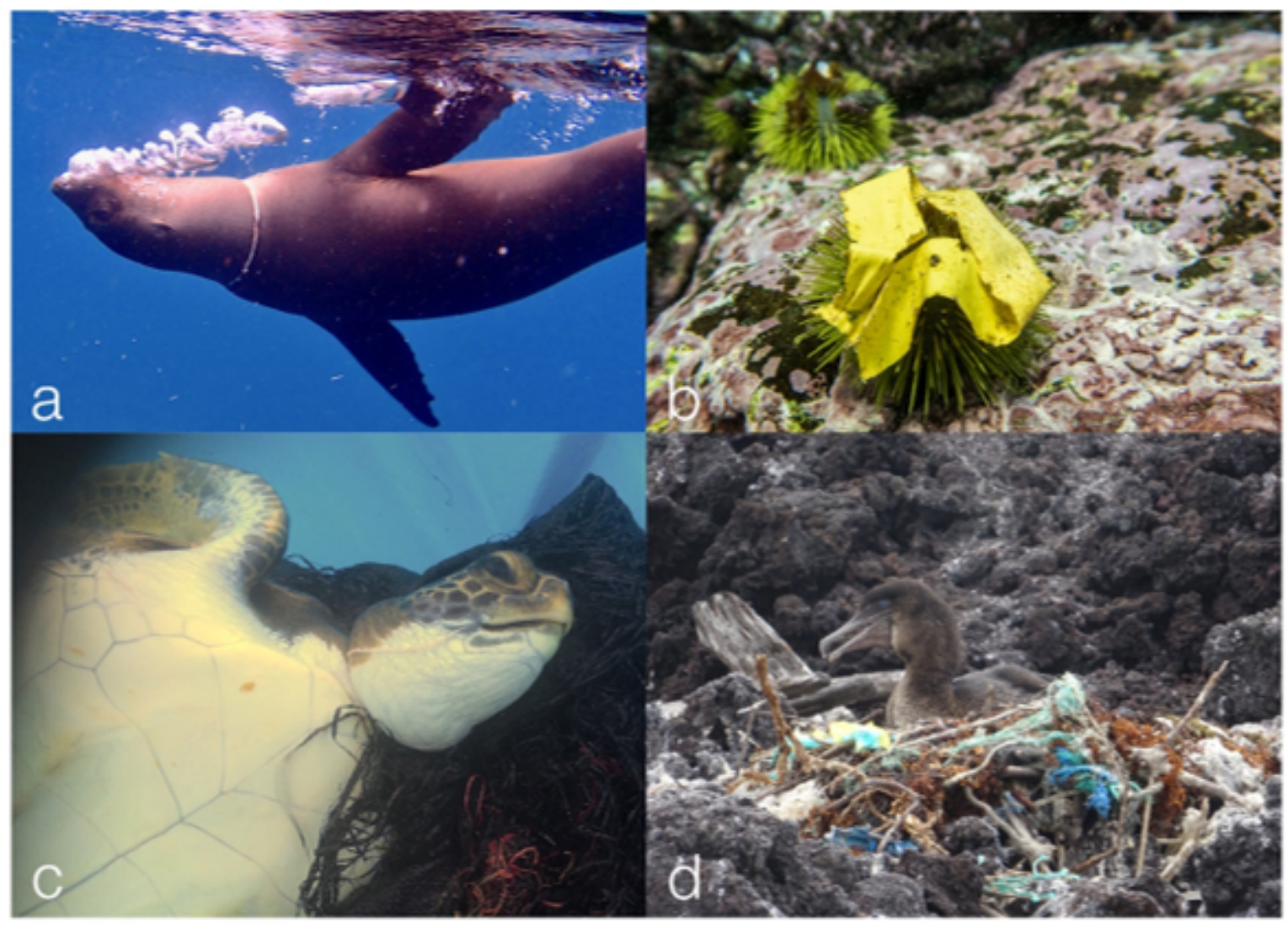

Figure 7

Photographic observations of Galapagos wildlife interacting with plastic items. (a) a Galapagos sea lion (Zalophus wollebaeki) with plastic sheeting wrapped around its neck (credit: Juan Pablo Muñoz-Pérez); (b) a Galapagos green sea urchin (Lytechinus semituberculatus) covered in yellow plastic tape (credit: Adam Porter); (c) a green sea turtle (Chelonia mydas) entangled in fishing net (credit: Manuel YepezRevelo); (d) a flightless cormorant (Phalacrocorax harrisi) on its nest including many plastic items, predominantly ropes (credit: Catherine Hobbs). 


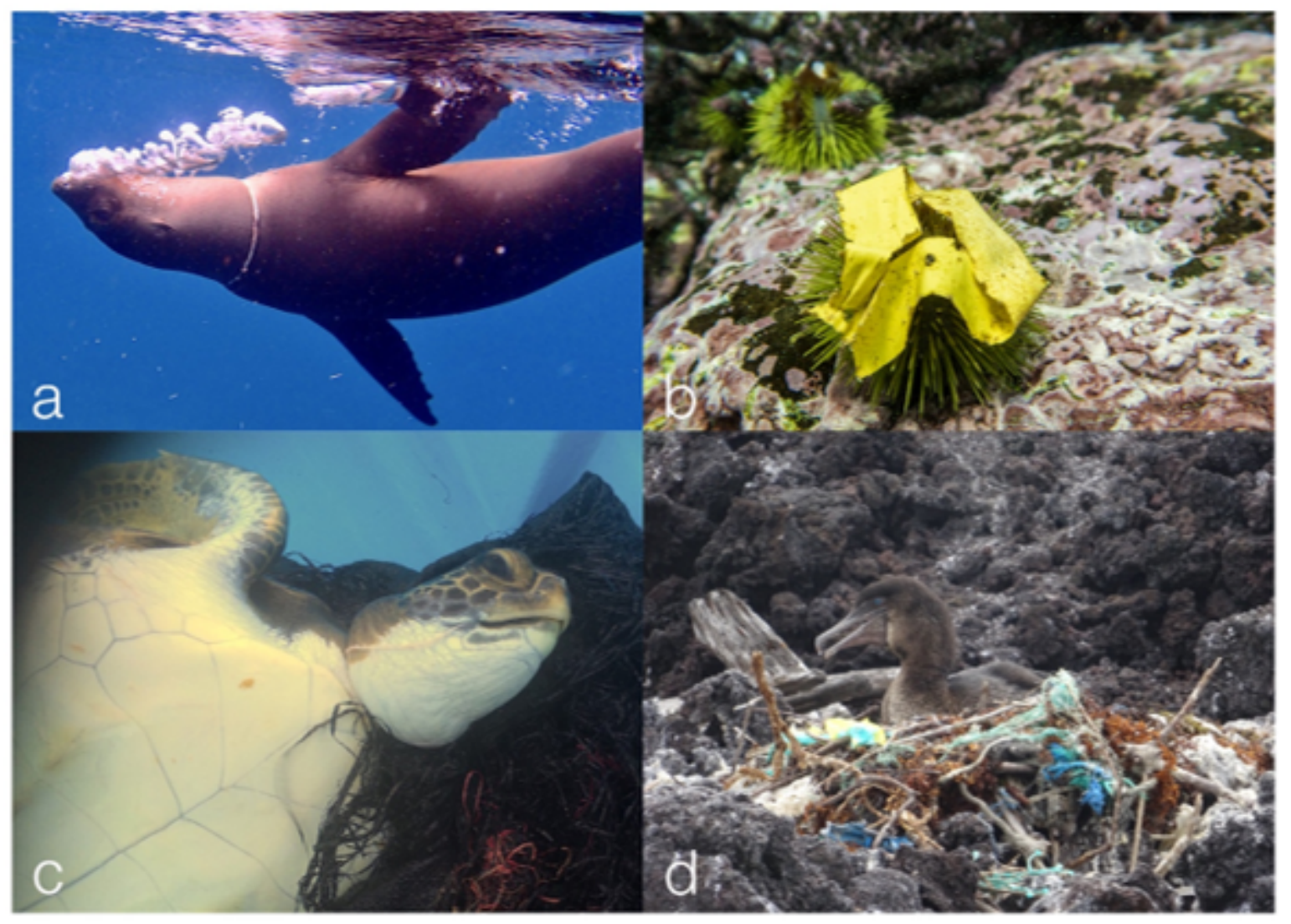

Figure 7

Photographic observations of Galapagos wildlife interacting with plastic items. (a) a Galapagos sea lion (Zalophus wollebaeki) with plastic sheeting wrapped around its neck (credit: Juan Pablo Muñoz-Pérez); (b) a Galapagos green sea urchin (Lytechinus semituberculatus) covered in yellow plastic tape (credit: Adam Porter); (c) a green sea turtle (Chelonia mydas) entangled in fishing net (credit: Manuel YepezRevelo); (d) a flightless cormorant (Phalacrocorax harrisi) on its nest including many plastic items, predominantly ropes (credit: Catherine Hobbs).

\section{Supplementary Files}

This is a list of supplementary files associated with this preprint. Click to download.

- GalapagosWildlifeRisksSupplementaryNov20.docx

- GalapagosWildlifeRisksSupplementaryNov20.docx 